TAPROBANICA, ISSN 1800-427X. November, 2020. Vol. 09, No. 02: pp. 174-193, pl. 51-52.

(C) Research Center for Climate Change and Department of Biology, Faculty of Mathematics \& Natural Sciences, University of Indonesia, Depok 16424, INDONESIA.

http://www.taprobanica.org/

https://doi.org/10.47605/tapro.v9i2.230

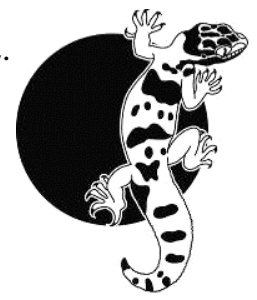

urn:Isid:zoobank.org:pub:D942BB4A-0A2F-4678-B2FC-0B448E5CC2EC

\title{
A NEW SPECIES OF THE Pareas hamptoni COMPLEX (SQUAMATA: SERPENTES: PAREIDAE) FROM THE GOLDEN TRIANGLE
}

\section{Li Ding ${ }^{1}$, Zening Chen ${ }^{2}$, Chatmongkon Suwannapoom ${ }^{3}$, Tan Van Nguyen ${ }^{4}$,}

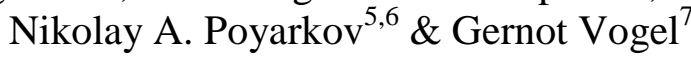

${ }^{1}$ Chengdu Institute of Biology, Chinese Academy of Sciences, Chengdu, China

${ }^{2}$ Guangxi Key Laboratory of Rare \& Endangered Animal Ecology, Guangxi Normal University, Guangxi, China

${ }^{3}$ School of Agriculture \& Natural Resources, University of Phayao, Phayao, Thailand

${ }^{4}$ Department of Species Conservation, Save Vietnam's Wildlife, Ninh Binh, Vietnam

${ }^{5}$ Department of Vertebrate Zoology, Faculty of Biology, Lomonosov Moscow State University, Moscow, Russia

${ }^{6}$ Joint Russian-Vietnamese Tropical Research \& Technological Center, Nghia Do, Cau Giay, Hanoi, Vietnam

${ }^{7}$ Society for Southeast Asian Herpetology, Im Sand 3, D-69115 Heidelberg, Germany

Corresponding authors.E-mails: tan@svw.vn ${ }^{4}$;n.poyarkov@gmail.com ${ }^{5}$;gernot.vogel@t-online.de ${ }^{7}$

\begin{abstract}
An investigation of the taxonomic status of Pareas hamptoni (Hampton's Slug snake) based on morphological and molecular data revealed a new distinct species from the Golden Triangle region (comprising parts of southern China, and adjacent Laos and Thailand). The new species is shown to be a sister species to $P$. hamptoni but can be separated from the latter by having 3-5 dorsal scale rows at midbody slightly keeled ( $v s$ 5-9 scales strongly keeled); a lower number of ventrals, 170-188 (vs 185-195); and a lower number of subcaudals, 67-91 (vs 91-99). The new species is currently known from northwestern Thailand, northern Laos, and the southern part of Yunnan Province in China at elevations of 1,160-2,280 m a.s.l. We suggest that the new species to be considered of Least Concern (LC) in the IUCN's Red List categories. Problems of taxonomy and actual distribution of the $P$. hamptoni complex are briefly discussed; our results show $P$. hamptoni is now reliably known only from Myanmar and Vietnam, but its occurrence in Yunnan Province of China is likely.
\end{abstract}

Key words: China, Indo-Burma, Laos, Pareas formosensis, Pareas mengziensis, Thailand

\section{Introduction}

The Asian snail-eating genus Pareas Wagler, 1830 (Pareidae) occurs throughout southern and south-eastern Asia. These snakes are mainly arboreal, nocturnal, and generally feed on slugs and snails (You et al. 2015, Uetz et al. 2020).
The genus Pareas is morphologically characterized by having medially smooth or keeled dorsal scales in 15 rows throughout the body; the ventrals preceded by a strongly enlarged preventral, larger than the ventrals; the subcaudals divided; the absence of mental 
groove; suboculars are usually present; supralabials usually not touching the eye (except in P. monticola and P. stanleyi); the anterior single inframaxillary shield lacking, three pairs of inframaxillaries, the first pair distinctly elongated, posterior inframaxillaries usually as long as wide or wider than long (Grossmann \& Tillack 2003). The reported high degree of morphological similarity makes species delineation in this genus quite challenging (Guo \& Deng 2009, Vogel 2015). Application of the integrative taxonomic approach combining evidence from morphological and molecular data resulted in the discovery of several previously unnoticed taxa (You et al. 2015, Wang et al. 2020, Vogel et al. 2020). Currently 19 species in the genus Pareas are regarded as valid, namely Pareas andersonii Boulenger; $P$. atayal You, Poyarkov \& Lin; P. boulengeri (Angel); P. carinatus (Wagler); P. chinensis (Barbour); P. formosensis (Van Denburgh); $P$. hamptoni (Boulenger); P. iwasakii (Maki); P. komaii (Maki); P. macularius (Theobald); $P$. menglaensis Wang, Che, Liu et al.; $P$. mengziensis Wang, Che, Liu et al.; $P$. margaritophorus (Jan); P. monticola (Cantor); $P$. modestus Theobald; $P$. nigriceps Guo \& Deng; $P$. nuchalis (Boulenger); $P$. stanleyi (Boulenger); and P. vindumi Vogel (see Guo et al. 2011, You et al. 2015, Uetz et al. 2020, Vogel et al. 2020). Hampton's Slug snake, Pareas hamptoni, was originally described by G.A. Boulenger in 1905 based on one single adult male from Mandalay Division, Myanmar (Boulenger 1905). This species has been reported to be widely distributed, ranging across mainland Southeast Asia from Myanmar in the west to Thailand, Indochina and southern China (Yunnan, Hainan, Guangdong and Guangxi provinces) in the east (Nguyen et al. 2009). However, since geographic variation of this species has never been examined across the different regions, its taxonomic status remained controversial and a number of misidentifications were made in the past (see You et al. 2015). Recently You et al. (2015) demonstrated that specimens identified as $P$. hamptoni from mainland China and Vietnam were closely related to $P$. formosensis that previously, was considered to be endemic to Taiwan. More recently, Wang et al. (2020) revised the taxonomy of this group, restricted the distribution of $P$. hamptoni sensu stricto to Myanmar, assigned populations from the southeastern part of mainland China to $P$. formosensis, and described a new species, $P$. mengziensis, from western Yunnan, China. However, the actual extent of the distribution of these species, as well as the taxonomic status of two $P$. hamptoni synonyms remains unclear. Presently Eberhardtia tonkinensis Angel, 1920 and Amblycephalus carinatus hainanus Smith, 1923 are considered to be junior synonyms of Pareas hamptoni (Wallach et al. 2014, Uetz et al. 2020). During our recent herpetological surveys throughout the Golden Triangle region (encompassing the southern part of Yunnan Province of China, Laos and Thailand), we collected a series of Pareas specimens which were originally identified as $P$. hamptoni (Vogel 2009, Teynié \& David 2010, Nguyen et al. 2020). However, further comprehensive analyses of molecular and morphological characters have demonstrated that these specimens form a lineage within the genus Pareas, which is different from all known congeners including $P$. hamptoni sensu stricto. Therefore, we herein describe it as a new species.

\section{Material and methods}

Material examined: For this study, a total 25 preserved specimens of the $P$. hamptoni complex were examined for their external morphological characters; eight specimens of the new species from China, Laos, and Thailand, 12 specimens of $P$. formosensis from eastern Indochina and southern China, and five specimens of $P$. hamptoni including the holotype. Measurements were taken with a slide-caliper to the nearest $0.1 \mathrm{~mm}$, except body and tail lengths, which were measured to the nearest one millimetre with a measuring tape. The number of ventral scales was counted according to Dowling (1951). The first enlarged scute preceding the ventrals (larger than the ventrals itself) was regarded as preventral; it was present in all examined specimens. Half ventrals were counted as one. The first scale under the tail meeting its opposite was regarded as the first subcaudal, and the terminal scute was not included in the number of subcaudals. The dorsal scale rows were counted at one head length behind head, at midbody, and at one head length before vent. The keeling was checked at midbody around half of the body length. The same was done for examination of the enlarged middorsal scale rows. In the number of supralabials touching the subocular, those only touching the presubocular were not included. 
Infralabials were considered to be those shields that were completely below a supralabial and bordering the mouth gap. Usually the last supralabial shield was a very large shield, much larger than other supralabials. Smaller shields behind this enlarged shield do not border the mouth gap (only the connecting muscle) and were excluded from the sublabial scale count, despite the fact that they were covered by the supralabials. Values for paired head characters were recorded on both sides of the head and were reported in a left/right order. The sex was determined by dissection of the ventral tail base. The examined materials for Pareas are listed in the Appendix. For comparison with other taxa, we relied on previously published data (e.g., Jiang 2004, Guo \& Zhao 2004, Guo \& Deng 2009, Stuebing et al. 2014, You et al. 2015, Vogel 2015, Vogel et al. 2020).

Museum abbreviations: AUP, School of Agriculture and Natural Resources, University of Phayao, Phayao, Thailand; CAS, California Academy of Sciences Museum, California, USA; CIB, Chengdu Institute of Biology, Chengdu, People's Republic of China; DL, Ding Lee's private collection, Chengdu, People's Republic of China; FMNH, Field Museum of Natural History, Chicago, USA; GP, Guo Peng's private collection, College of Life Science and Food Engineering, Yibin University, Yibin, People's Republic of China; LSUHC, La Sierra University Herpetological Collection, Riverside, California, USA; KIZ, Kunming Institute of Zoology, Chinese Academy of Sciences, Kunming, People's Republic of China; MNHN, Muséum National d'Histoire Naturelle, Paris, France; NHMUK, The Natural History Museum, London, UK; NMNS, National Museum of Natural Science, Taichung, Taiwan, China; NMW, Naturhistorisches Museum Wien, Vienna, Austria; QSMI, Queen Saovabha Memorial Institute, Thai Red Cross Society, Bangkok, Thailand; YPX, Field number of KIZ; $\mathrm{ZMB}$, Zoologisches Museum für Naturkunde der Humboldt-Universität zu Berlin, Berlin, Germany; ZMH, Zoologisches Institut und Museum, Universität Hamburg, Hamburg, Germany; ZMMU, Zoological Museum of Moscow University, Moscow, Russia. Other abbreviations: SVL, snout-vent length; TaL, tail length; TL, total length; Mt., mountain; NP, national park; NR, natural reserve; a.s.l., above sea level.

Molecular methods: For those specimens for which tissue samples were available, we performed molecular phylogenetic analyses to test the differences observed from the morphological data (Table 1). For molecular analyses, we extracted the total genomic DNA from ethanol-preserved liver or muscle tissue using standard phenol-chloroform-proteinase $\mathrm{K}$ extraction protocol following Hillis et al. (1996), with consequent isopropanol precipitation. The isolated genomic DNA was visualized in agarose electrophoresis in the presence of ethidium bromide. We measured DNA concentration in $1 \mu \mathrm{l}$ using NanoDrop 2000 (Thermo Scientific), and adjusted it to ca. 100 ng DNA $/ \mu \mathrm{L}$. To assess the phylogenetic relationships within the Pareidae, we amplified 1126 bp long fragment of mtDNA cytochrome $b$ gene (cyt $b$ ), 680 bp long fragment of mtDNA NADH dehydrogenase subunit 4 gene (ND4), and a 734 bp long fragment of nuclear oocyte maturation factor mos gene (c-mos). These genes are widely applied as phylogenetic markers in biodiversity surveys in various snake groups, including the family Pareidae (e.g. Guo et al. 2011; Loredo et al. 2013; You et al. 2015; Deepak et al. 2020; Li et al. 2020; Wang et al. 2020; Vogel et al. 2020). We performed DNA amplification in $20 \mu \mathrm{l}$ reactions using ca. $50 \mathrm{ng}$ genomic DNA, $10 \mathrm{nmol}$ of each primer, $15 \mathrm{nmol}$ of each dNTP, $50 \mathrm{nmol}$ additional $\mathrm{MgCl} 2$, Taq PCR buffer (10 mM Tris-HCl, pH 8.3, $50 \mathrm{mM}$ $\mathrm{KCl}, 1.1 \mathrm{mM} \mathrm{MgCl} 2$ and $0.01 \%$ gelatine) and 1 $\mathrm{U}$ of Taq DNA polymerase. Primers used in PCR and amplification are summarized in Table 2 . The PCR conditions for cyt $b$ and $c$-mos genes followed You et al. (2015) and included denaturation at $94{ }^{\circ} \mathrm{C}$ for $3 \mathrm{~min}$, followed by 35 cycles at $94{ }^{\circ} \mathrm{C}$ for $30 \mathrm{~s}, 52{ }^{\circ} \mathrm{C}$ for $40 \mathrm{~s}$ and 72 ${ }^{\circ} \mathrm{C}$ for $90 \mathrm{~s}$, with a final extension at $72{ }^{\circ} \mathrm{C}$ for 10 min. The PCR conditions for ND4 gene were as follows: initial denaturation at $94{ }^{\circ} \mathrm{C}$ for 3 min, followed by 15 cycles at $94{ }^{\circ} \mathrm{C}$ for $60 \mathrm{~s}$, annealing for $60 \mathrm{~s}$ and $72{ }^{\circ} \mathrm{C}$ for $60 \mathrm{~s}$, with annealing temperature reducing $0.5{ }^{\circ} \mathrm{C}$ every cycle from $60{ }^{\circ} \mathrm{C}$, followed by 19 cycles at 92 ${ }^{\circ} \mathrm{C}$ for $60 \mathrm{~s}, 52{ }^{\circ} \mathrm{C}$ for $60 \mathrm{~s}$ and $72{ }^{\circ} \mathrm{C}$ for $60 \mathrm{~s}$, with a final extension step at $72{ }^{\circ} \mathrm{C}$ for $15 \mathrm{~min}$. All amplifications were run using an iCycler Thermal Cycler (Bio-Rad). PCR products were loaded onto $1.5 \%$ agarose gels in the presence of ethidium bromide and visualized in electrophoresis. The successful targeted PCR products were outsourced to Evrogen ${ }^{\circledR}$ (Moscow, Russia) for PCR purification and sequencing; sequence data collection and visualization was performed on an ABI 3730xl 
Automated Sequencer (Applied Biosystems). We deposited the newly obtained sequences in GenBank under the accession numbers MW287022-MW287080 (Table 1).

Phylogenetic analyses: To reconstruct the phylogenetic relationships within the genus Pareas, we aligned the newly obtained cyt $b$, ND4 and $c$-mos sequences together with representative sequences of all 19 currently recognized species of Pareas and one undescribed species Pareas sp. from northeastern India, as well as five outgroup species of Asthenodipsas as well as Aplopeltura boa. The sequence of Xylophis captaini (Pareidae: Xylophinae) was used to root the tree following the phylogenetic data of Deepak et al. $(2018,2020)$ (Table 1). In total, sequences for 52 specimens of Pareidae were included in the final analysis, comprising all currently recognized species of the genus Pareas, and including 34 sequences of Pareas hamptoni species group members from India, Myanmar, China, southernmost Japan, Vietnam, Laos, and Thailand (Fig. 1). The nucleotide sequences were initially aligned in MAFFT v.6 (Katoh et al. 2002) with default parameters, and were subsequently checked by eye in BioEdit 7.0.5.2 (Hall 1999) and slightly adjusted. The mean uncorrected genetic $p$-distances between sequences were calculated with MEGA 6.0 (Tamura et al. 2013). Phylogenetic trees were estimated for the combined mitochondrial DNA fragments (cyt $b$ and ND4) and nuclear gene (c$m o s$ ) dataset. The total evidence analysis was performed as the approximately unbiased treeselection test (AU-test; Shimodaira 2002) conducted using Treefinder v.March 2011 (Jobb 2011) did not reveal statistically significant topological differences between mtDNA and nuDNA topologies. Phylogenetic relationships of Pareinae were inferred using Bayesian Inference (BI) and Maximum Likelihood (ML) approaches. A Maximum Likelihood (ML) analysis was implemented using the IQ-TREE webserver (Nguyen et al. 2015; Trifinopoulos et al. 2016) preceded by the selection of substitution models using the Bayesian Information Criterion (BIC) in ModelFinder (Kalyaanamoorthy et al. 2017) which selected $\mathrm{GTR}+\mathrm{I}+\mathrm{G}$ for the first and the third codon positions of cyt $b, \mathrm{GTR}+\mathrm{G}$ for the second codon position of cyt $b$, and the third codon position of $N D 4$ and $c$-mos, $\mathrm{HKY}+\mathrm{G}$ for the first and the second codon positions of $N D 4, \mathrm{~K} 2 \mathrm{P}$ for the first codon position of $c-m o s$, and $\mathrm{K} 2 \mathrm{P}+\mathrm{I}$ for the second codon position of $c-m o s$, as suggested by the Akaike Information Criterion (AIC). When the same model was proposed to different codon positions of a given gene, they were treated as a single partition; which resulted in seven partitions in total. One-thousand bootstrap pseudoreplicates via the ultrafast bootstrap (UB; Hoang et al. 2018) approximation algorithm were employed, and nodes having UB values of 95 and above were considered strongly supported (Minh et al. 2013). We considered nodes with values of 90-94 to be wellsupported. A Bayesian phylogenetic tree (BI) was estimated using MrBayes 3.1.2 (Ronquist \& Huelsenbeck 2003). Metropolis-coupled Markov chain Monte Carlo (MCMCMC) analyses were run with one cold chain and three heated chains for one million generations and sampled every 100 generations. Two independent MCMCMC runs were performed and checked for the effective sample sizes (ESS) were all above 200 by exploring the likelihood plots using TRACER v1.6 (Rambaut \& Drummond 2007). We discarded the initial 1000 trees as burn-in. We assessed the confidence in tree topology by the posterior probability (PP) (Huelsenbeck \& Ronquist 2001). Nodes with Bayesian posterior probabilities (BPP) of 0.95 and above were considered strongly supported (Wilcox et al. 2002). We considered nodes with values of 0.90-0.94 as well-supported.

\section{Results}

Phylogenetic data: The ML and BI analyses recovered trees with very similar topologies, and the ML topology used here (Fig. 2) agreed well with the earlier phylogenies of the genus Pareas (Guo et al. 2011, You et al. 2015, Wang et al. 2020, Vogel et al. 2020). Phylogenetic relationships among the three genera of Pareidae were resolved sufficiently, suggesting sister relationships between the genera Aplopeltura and Pareas (96/1.0; hereafter nodal support values given for UB/BPP, respectively), and a more distant phylogenetic position of Asthenodipsas. The monophyly of the genus Asthenodipsas was poorly supported (93/0.86), while the monophyly of the genus Pareas with respect to other genera was strongly supported (97/1.0) (Fig. 2). All species of Pareas were clustered in five major clades, corresponding to groups of closely related species, in accordance with the results of Vogel et al. (2020): 


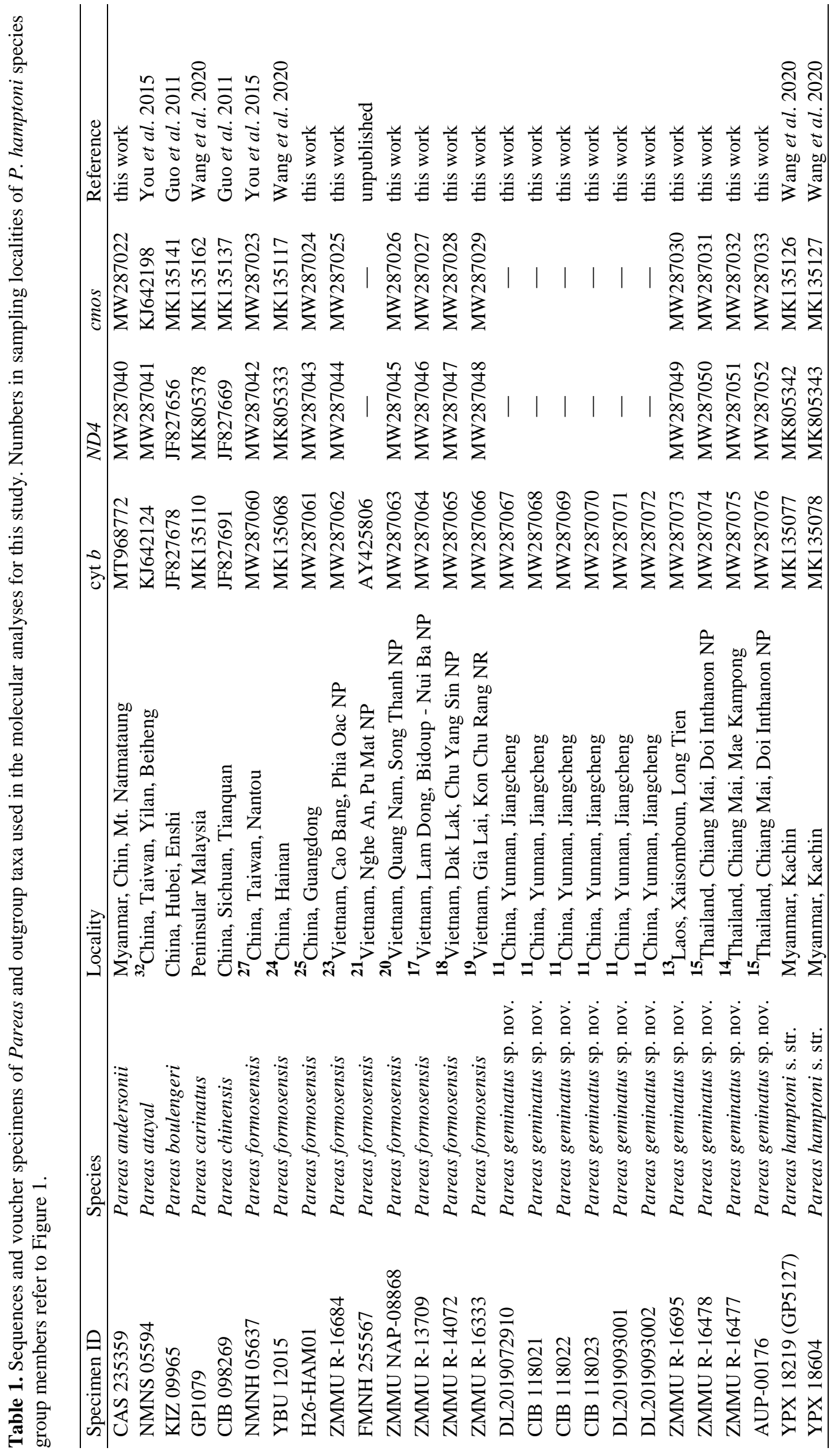




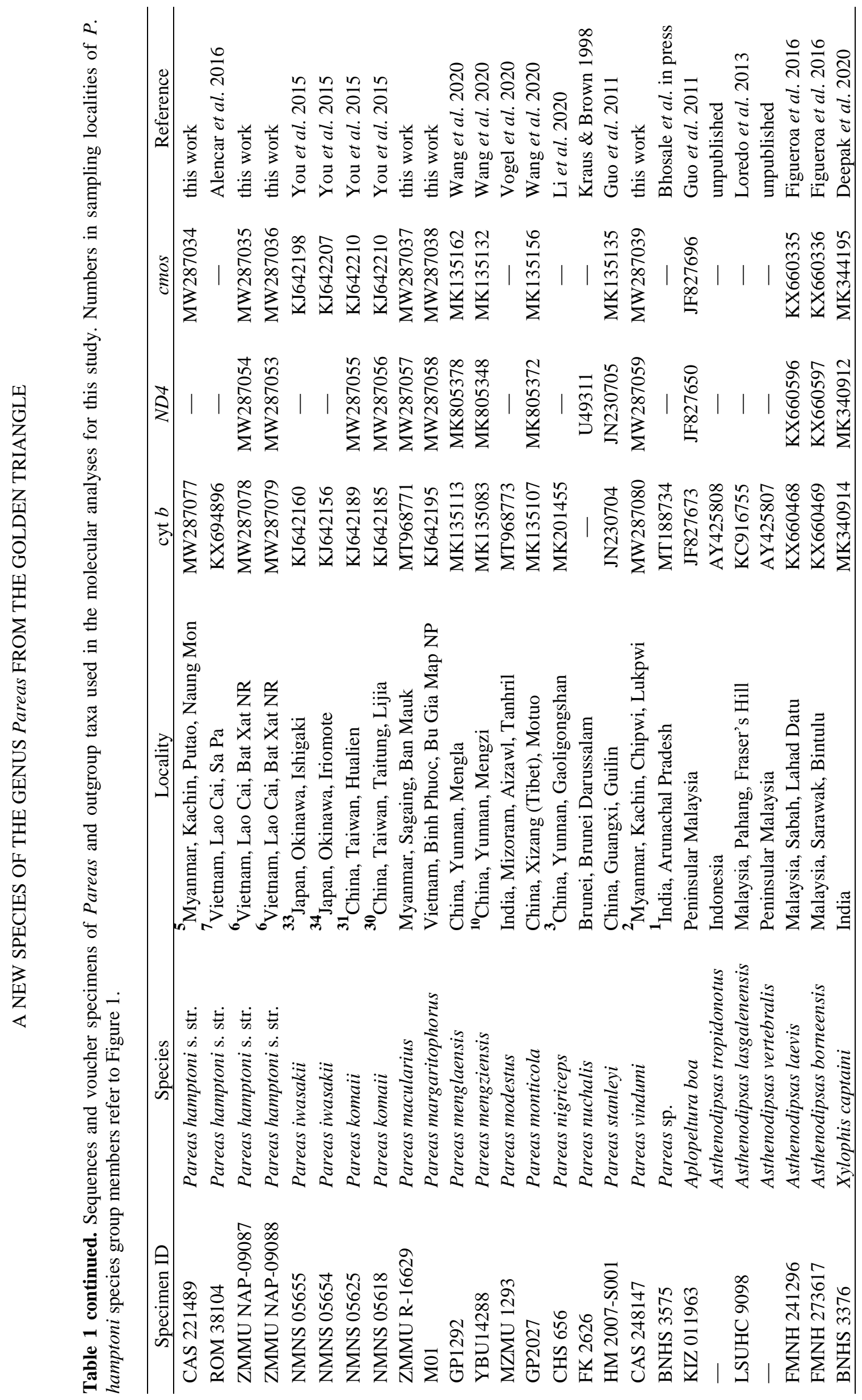




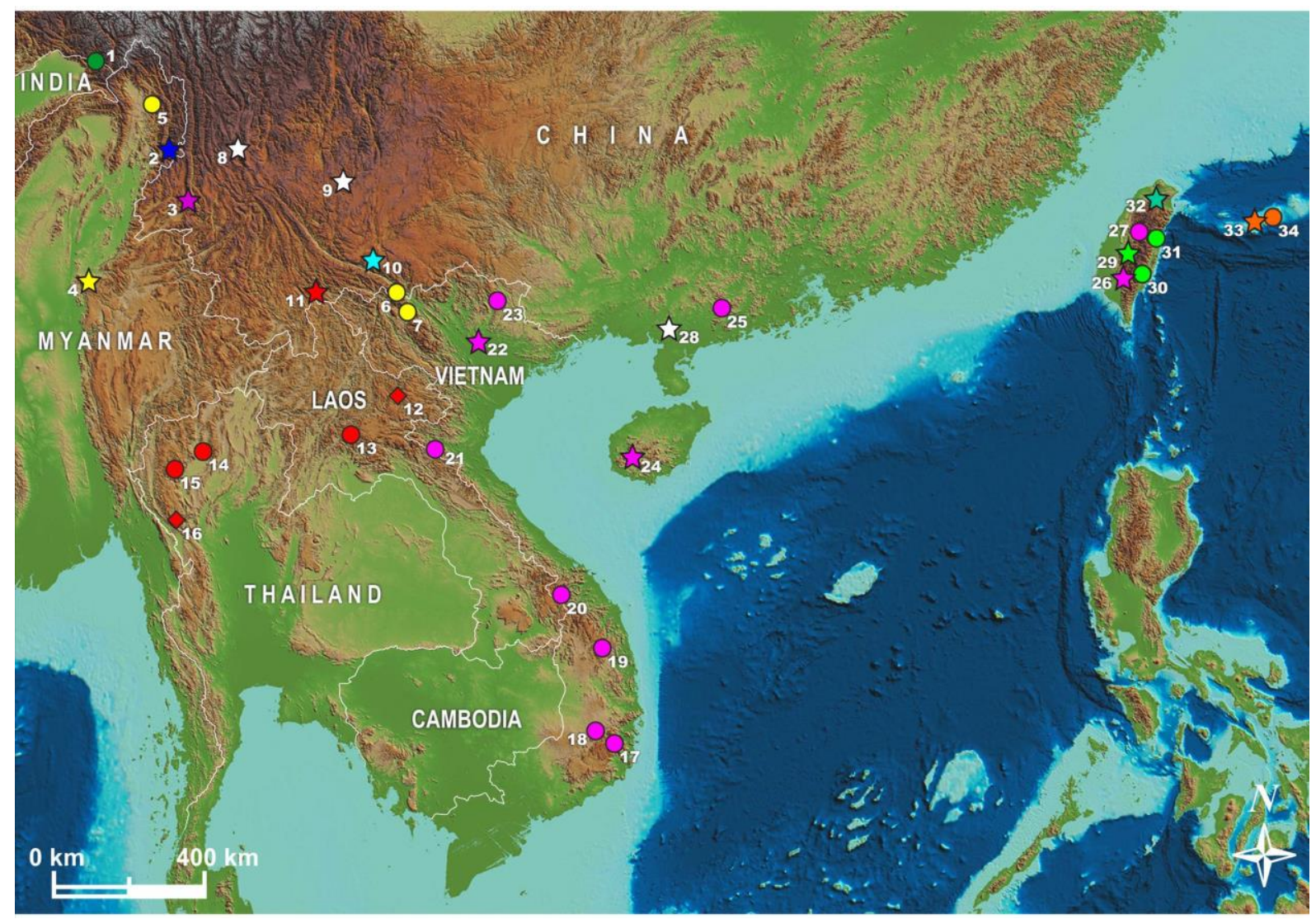

Figure 1. Distribution of Pareas hamptoni species complex: type localities (star); populations for which molecular/morphological data available (filled icons, colours correspond to those in Fig. 2); populations of unclear taxonomic status (white icons).

Pareas sp.: (1) India, Arunachal Pradesh (Bhosale et al. in press); Pareas vindumi: (2) Myanmar, Kachin, Chipwi, Lukpwi (Vogel 2015); Pareas nigriceps: (3) China, Yunnan, Gaoligongshan (Guo \& Deng 2009); Pareas hamptoni sensu stricto: (4) Myanmar, Mandalay, Mogok (Boulenger 1905), (5) Myanmar, Kachin, Putao, Naung Mon (this paper), (6) Vietnam, Lao Cai, Bat Xat NR (this paper), (7) Vietnam, Lao Cai, Sa Pa (Alencar et al. 2016); 'Amblycephalus yunnanensis': (8) China, Yunnan, Talifu [Dali County] (Vogt 1922); 'Amblycephalus niger': (9) China, Yunnan, Kunming (Pope 1928); Pareas mengziensis: (10) China, Yunnan, Mengzi (Wang et al. 2020); Pareas geminatus sp. nov.: (11) China, Yunnan, Jiangcheng (this paper), (12) Laos, Houaphanh (this paper), (13) Laos, Xaisomboun, Long Tien (this paper), (14) Thailand, Chiang Mai, Mae Kampong (this paper), (15) Thailand, Chiang Mai, Doi Inthanon NP (this paper), (16) Thailand, Tak, between Uphang and Mae Sot (Vogel 2010, this paper); Pareas formosensis: (17) Vietnam, Lam Dong, Bidoup-Nui Ba NP (this paper), (18) Vietnam, Dak Lak, Chu Yang Sin NP (this paper), (19) Vietnam, Gia Lai, Kon Chu Rang NR (this paper), (20) Vietnam, Quang Nam, Song Thanh NP (this paper), (21) Vietnam, Nghe An, Pu Mat NP (this paper), (22) Vietnam, Vinh Phuc, Tam Dao NP (Angel 1920; type locality of Eberhardtia tonkinensis), (23) Vietnam, Cao Bang, Phia Oac NP (this paper), (24) China, Hainan (Smith 1923; type locality of Amblycephalus carinatus hainanus), (25) China, Guangdong (this paper), (26) China, Taiwan, Kanshirei [Kuantzu Ling] (Van Denburgh 1909; type locality of Amblycephalus formosensis), (27) China, Taiwan, Nantou (You et al. 2015); 'Amblycephalus kuangtungensis': (28) China, Guangdong, Mt. Longtoushan (Vogt 1922); Pareas komaii: (29) China, Taiwan, Arisan [Alishan NP] (Maki 1931), (30) China, Taiwan, Taitung, Lijia (You et al. 2015), (31) China, Taiwan, Hualien (You et al. 2015); Pareas atayal: (32) China, Taiwan, Yilan, Beiheng Rd. (You et al. 2015); Pareas iwasakii: (33) Japan, Okinawa, Ishigaki (Maki 1937, You et al. 2015), (34) Japan, Okinawa, Iriomote (You et al. 2015). 


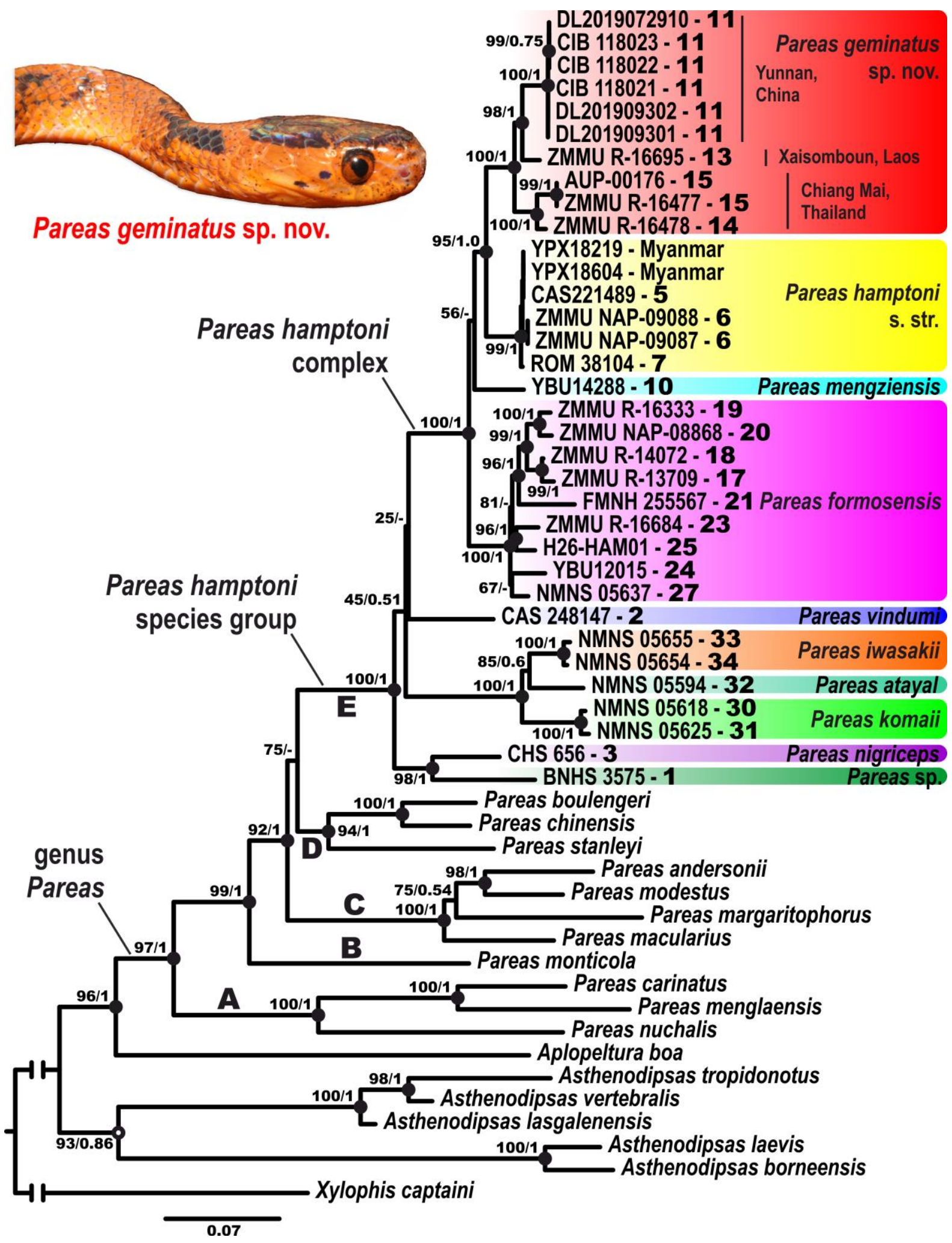

Figure 2. Majority-rule consensus tree from 1000 ML bootstrap pseudoreplicates of the Pareas hamptoni species group derived from the analysis of $1126 \mathrm{bp}$ of cyt $b, 678 \mathrm{bp}$ of ND4, and $734 \mathrm{bp}$ of $c$-mos gene fragments. Black circles represent nodes the UB and BPP support > 90 and 0.90, respectively; the white circle represents a node with UB support $>90$ only; nodes lacking circles are unsupported. For voucher specimen information and GenBank accession numbers see Table 1; values in bold after specimen ID correspond to locality numbers (Fig. 1 and Table 1). Photograph showing Pareas geminatus sp. nov. from Jiangcheng County, Yunnan Province, China, by Shengchao Shi. 
(1) Pareas carinatus species group (Fig. 2, clade A; 100/1.0) is composed of $P$. carinatus, $P$. menglaensis, and $P$. nuchalis; the former two species form a clade (100/1.0). This species group forms a highly divergent lineage, sister to all other congeners (99/1.0).

(2) Pareas monticola (Fig. 2, lineage B; $100 / 1.0)$ is an orphaned species from Himalaya that forms a well-supported sister lineage with respect to all remaining Pareas species of clades C-E (92/1.0); phylogenetic relationships among the latter clades are essentially not resolved.

(3) Pareas margaritophorus species group (Fig. 2 , clade $C ; 100 / 1.0)$ is composed of $P$. margaritophorus, $P$. macularius, $P$. modestus and $P$. andersonii; phylogenetic relationships among the members of this group are not resolved, though the two latter species form a clade (98/1.0).

(4) Pareas chinensis species group (Fig. 2, clade D; 94/1.0) is composed of $P$. chinensis, $P$. boulengeri and $P$. stanleyi; with the former two species forming a clade (100/1.0).

(5) Pareas hamptoni species group (Fig. 2, clade E; 100/1.0) includes at least ten lineages with species level of differentiation from Himalaya, northern Indochina, Annamite (Truong Son) Range., southern China, including the islands of Hainan and Taiwan, and the southernmost islands of the Ryukyu Archipelago (Yaeyama Group) of Japan (Fig. 1).

Phylogenetic relationships among the species composing the $P$. hamptoni species group remain essentially unresolved. An undescribed species, Pareas sp. from East Himalaya in India, formed a well-supported clade with $P$. nigriceps from the Mt. Gaoligongshan in western Yunnan, China (98/1.0; see Figs. 1 and 2). A group of closelyrelated species from the Pacific islands of Taiwan and the Yaeyama Group of the Ryukyus formed a strongly supported monophylum composed of $P$. atayal, $P$. iwasakii and $P$. komaii (100/1.0; Figs. 1 and 2). The phylogenetic position of $P$. vindumi from northern Myanmar within the group remained unresolved (Figs. 1 and 2). Finally, the lineages until recently regarded as $P$. hamptoni sensu lato formed a strongly supported clade (100/1.0), which we now refer to as $P$. hamptoni complex (Fig. 2). Overall, our analysis revealed the four major lineages of species-level differentiation within the P. hamptoni complex (Fig. 2). The sample of $P$. formosensis from Taiwan (locality 27, Fig. 1) clustered in one group with specimens from southern China (localities 24 previously referred to as Amblycephalus carinatus hainanus, Fig. 1), northern Vietnam (localities 21-23 previously referred to as Eberhardtia tonkinensis, Fig. 1), and the mountains of the Tay Nguyen Region in central and southern Vietnam (localities 17-20, Fig. 1). The sample of $P$. mengziensis from eastern Yunnan in China formed a lineage with unresolved phylogenetic affinities (locality 10, Figs. 1 and 2). The samples of $P$. hamptoni (95/1.0) were divided into two reciprocally monophyletic lineages, one of which included samples from northern Myanmar (locality 5) and the Mt. Hoang Lien Son in the north-eastern part of Vietnam (localities 6-7, Fig. 1), and corresponded to $P$. hamptoni sensu stricto (99/1.0). The second lineage (100/1.0) included samples from the mountains of southern Yunnan (locality 11), Laos (locality 13) and northern Thailand (localities 14-15, Fig.1).

Genetic distances: The interspecific uncorrected genetic $p$-distances in cyt $b$ gene within Pareas varied from $p=5.5 \%$ (between $P$. hamptoni sensu stricto and $P$. mengziensis) to $p=25.3 \%$ (between P. menglaensis and Pareas sp. from India). The divergence between the two sister lineages of ' $P$. hamptoni' was found to be $p=7.6 \%$; while the intraspecific distances varied from $0.5 \%$ within $P$. hamptoni sensu stricto to $p=4.0 \%$ within the new lineage from southern Yunnan, Laos and Thailand (Table 3).

\section{Taxonomy}

Based on our updated phylogeny of Pareinae, and the high degree of uncorrected pairwise sequence divergence between the two lineages presently assigned to ' $P$. hamptoni' as well as the stable morphological and chromatical differences reported below, we hypothesize that the populations of the $P$. hamptoni complex from the Golden Triangle region (northwestern Thailand, northern Laos and southernmost part Yunnan Province in China) represent a discretely diagnosable lineage which shows no evidence of reciprocity with any other lineage and as such, should be accorded species status, and is formally described below. 
กิก

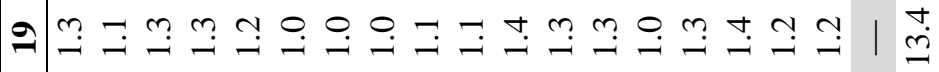

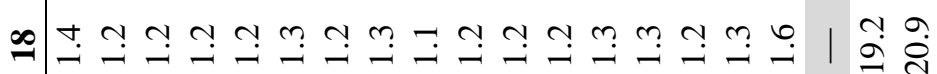
분

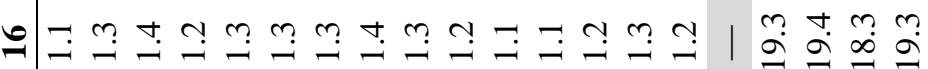

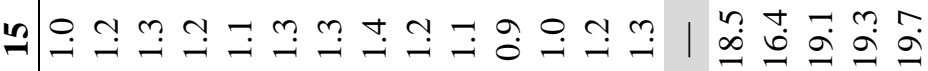

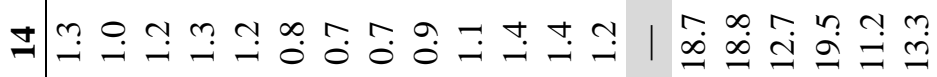

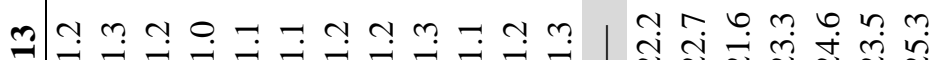
它

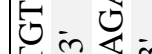
包它出 不进的 过论

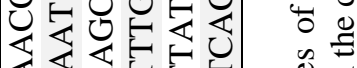
过安包造 $\ll<\ll<0$ 过出论 还安究

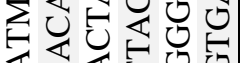

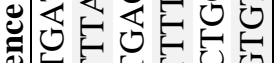

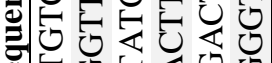

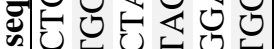

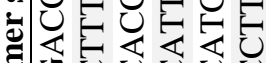

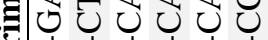

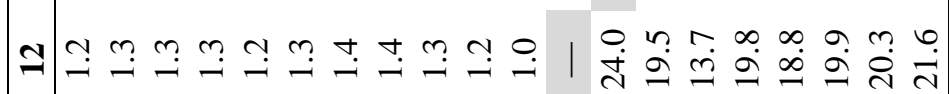

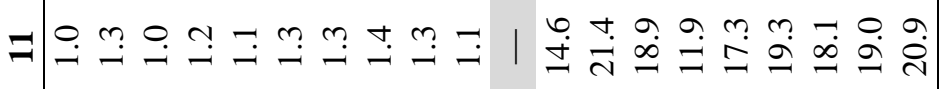
-

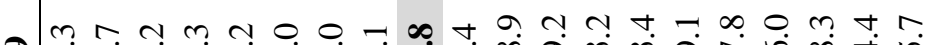

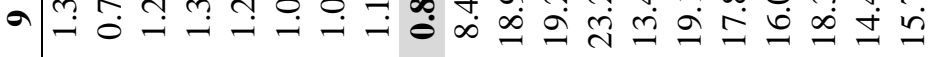

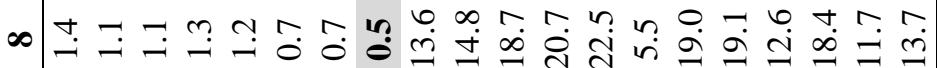

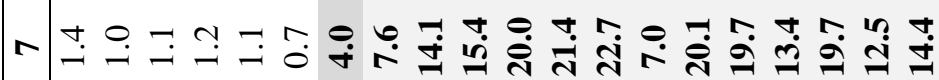

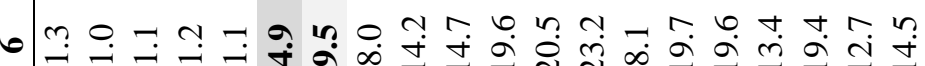

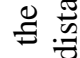
एँ 䓪 of

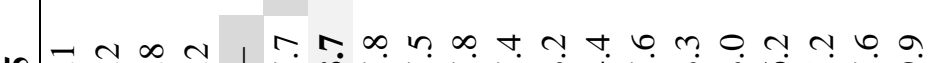
n

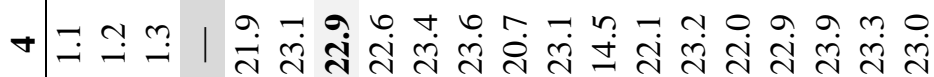
m ఇ

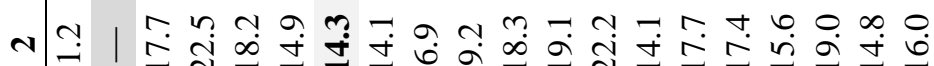
N- 
Pareidae Romer, 1956

Pareas Wagler, 1830

Pareas geminatus sp. nov.

[urn:1sid:zoobank.org:act:8F0D1286-933F-45A7-B557FEBC23751B53]

(Figs. 3-4; Table 4)

Pareas hamptoni - Vogel 2010; Teynié \& David 2010 [partim].

Holotype. Adult male, CIB 118021, collected from Jiangcheng County (21.207556 N, 94.020056 E; alt. 2,280 $\mathrm{m}$ a.s.1.), Yunnan Province, China, by Ding Li on 21 May 2006.

Paratypes $(\boldsymbol{n}=\mathbf{5})$. Adult females, CIB 118022 and CIB 118023, collected from Jiangcheng County (22.603453 N, 101.882167 E; alt. 1,272 m a.s.l.), Yunnan Province, China; adult male, MNHN 0171S, collected from Houaphanh Province, Laos (no exact locality data); subadult male, ZMMU R-16695, collected from Long Tien, Xaisomboun Province, Laos; adult female, QSMI 1013, collected from Tak Province (approx. 16.425833 N, $99.000000 \mathrm{E}$; alt. 1,160 $\mathrm{m}$ a.s.l.), Thailand.

Other material examined $(n=6)$. Adult male, DL20190930002 (22.619374 N, 101.473156 E, alt. $1,253 \mathrm{~m}$ a.s.l.); adult male, DL2019072910 (22.603453 N, $101.882167 \mathrm{E}$; alt. 1,272 $\mathrm{m}$ a.s.l.); adult female, DL2019093001 (22.603424 N, 101.882041 E, alt. 1,227 m a.s.l.; all from Jiangcheng County, Yunnan Province, China; adult males, AUP-00176, ZMMU R16477, ZMMU R-16478, collected from Doi Inthanon NP, Chiang Mai Province, Thailand.

Diagnosis. Pareas geminatus sp. nov. differs from all congeners by the combination of the following morphological characters: a slender, yellow-brown, medium-sized snake (total length $566 \mathrm{~mm}$ ); one or two anterior temporals; loreal not contacting the eye; prefrontal contacting the eye; one preocular; slightly enlarged median vertebral row; usually 7 (6-8) supralabials; 8 infralabial scales; $3-5$ scale rows slightly keeled at midbody; $170-188$ ventrals lacking lateral keels; 75-91 subcaudals, all divided; slightly billowing vertical dark bars on the trunk; two slight thin black postorbital stripes starting from lower and upper edges of postorbital scales; lower postorbital stripe reaching the anterior part of seventh supralabial, not continuing to the lower jaw and chin; the left and right upper postorbital stripes merge forming a black nuchal collar.
Description of the holotype: Body slender and laterally flattened; head comparatively large, elongate, clearly distinct from the thin neck (head more than twice the width of the neck near the head base); snout blunt; eye rather large, pupil vertical and slightly elliptical. SVL 428 mm; TaL 138 mm; TL 566 mm; TaL/TL: 0.244. Dorsal scales in 15-15-15 rows, slightly keeled in 5 scale rows at midbody, lacking apical pits; vertebral scales slightly enlarged (one mesial row); outermost dorsal scale rows not enlarged; ventrals $180 \quad(+1$ preventral $)$, lacking lateral keels; subcaudals 79, all divided; cloacal plate single.

Rostral not visible from above; single nasal; two internasals, much wider than long, narrowing and slightly curving back laterally (in dorsal view), anteriorly in contact with rostral, laterally in contact with nasal and loreal, posteriorly in contact with prefrontal, not contacting preocular; two large irregular pentagonal prefrontals, much larger than internasals and with a slightly diagonal suture between them, contacting the eye; frontal hexagonal in shape with the lateral sides converging posteriorly, longer than wide, smaller than parietals; presubocular absent; on the both sides subocular and postocular fused into a crescent-shaped scale; one large loreal, not contacting the eye, contacting prefrontal, internasal, nasal, $2^{\text {nd }}$ supralabial and subocular; 6/7 supralabials, $3^{\text {rd }}-5^{\text {th }}$ SL touching the subocular, none reaching the eye, $6^{\text {th }}$ by far the largest, elongate; $1 / 1$ supraocular; $1 / 1$ anterior temporals; $2 / 2$ posterior temporals; $8 / 8$ infralabials, anterior most in contact with opposite one along midline, bordering mental, anterior 5 pairs of infralabials bordering anterior chin shields; 4 pairs of chin shields interlaced, $2^{\text {nd }}$ pair very small, no mental groove under chin and throat; anterior chin shields relatively large, much longer than broad, followed by two pairs of chin shields that are much broader than long.

Colouration. In preservative, dorsal surface head black, two black spots behind each eye and above the angle of the mouth respectively on each side of head; ventral surface of head uniformly yellowish. Dorsal surface body yellowish-brown, with about 56 dark faint bands and a few tiny black spots on each scale of the back; the black bands tapering downward on the sides of body and tail, sometimes crossing the vertebral; ventral surface body and tail pale with very sparse small black spots concentrating laterally, tail tip black. 


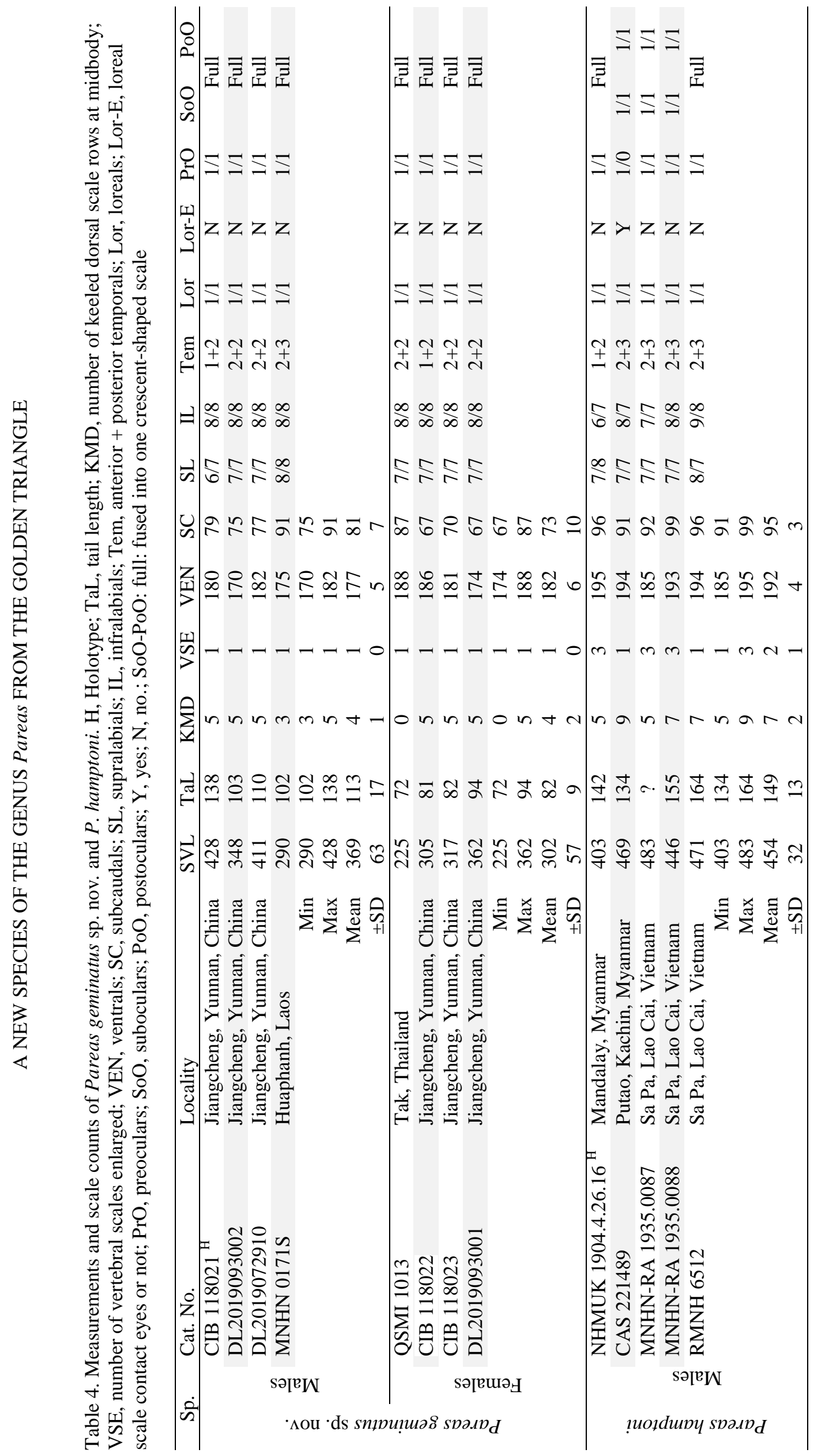




\section{Plate 51}

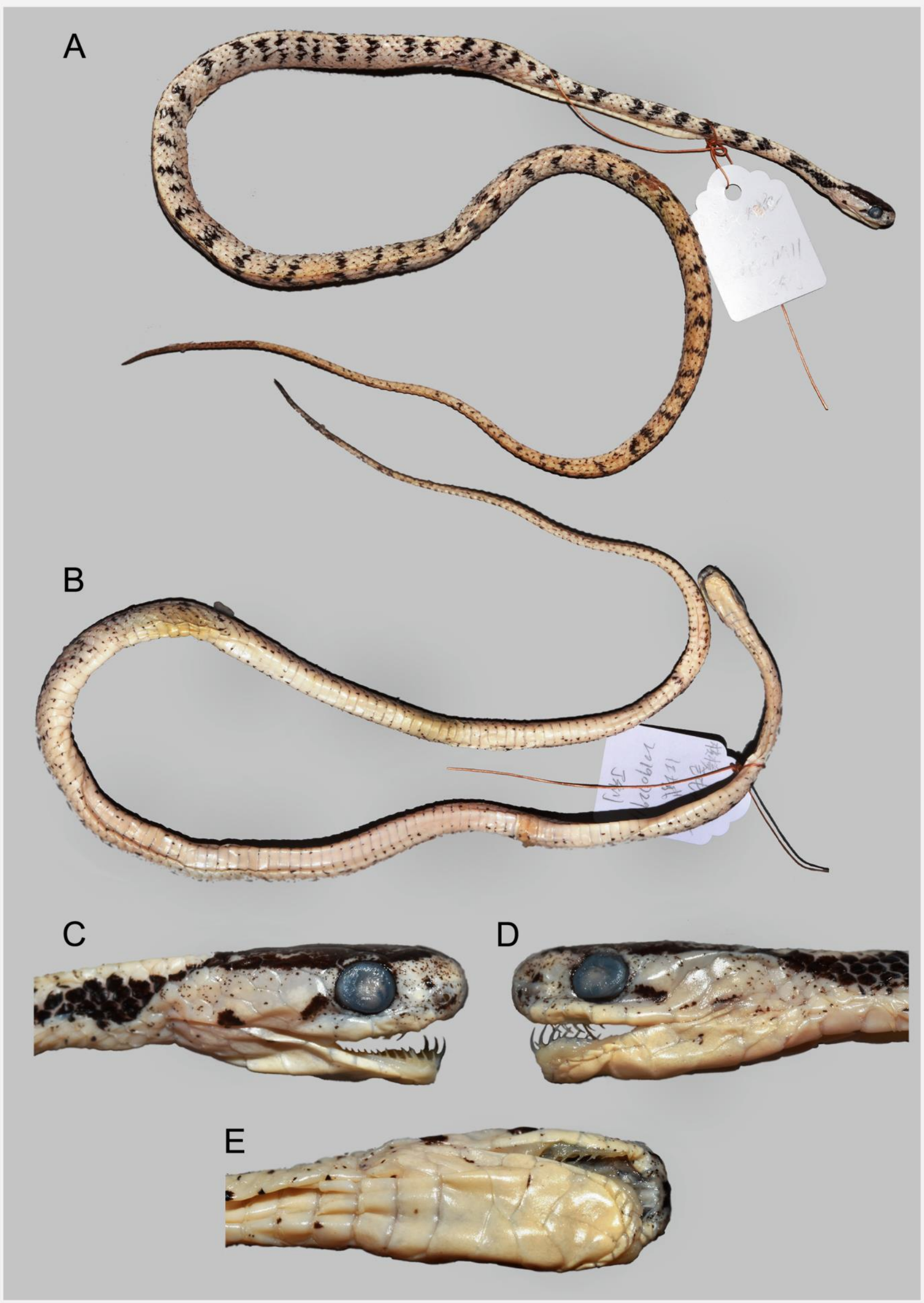

Figure 3. Holotype of Pareas geminatus sp. nov. (CIB 118021, adult male): (A) dorsal and (B) ventral views of the body; and the head in (C) lateral (right side), (D) lateral (left side), and (E) ventral views. C Photos G. Vogel 


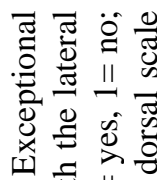

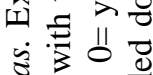

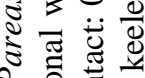

2.

要远

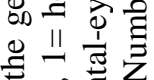

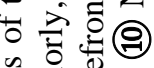

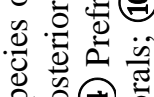

究。

喝.

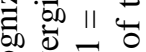

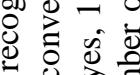

至

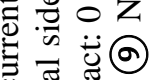

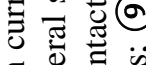

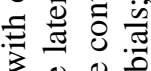

可

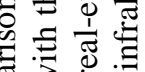

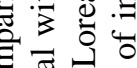

ชิ

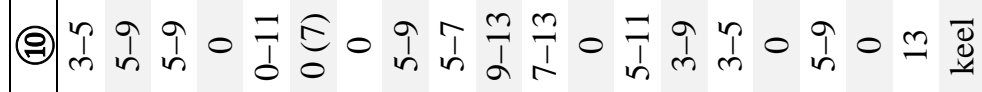

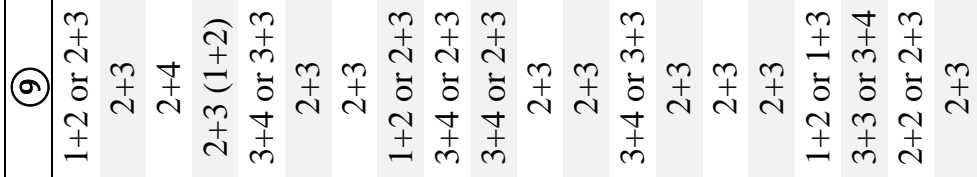

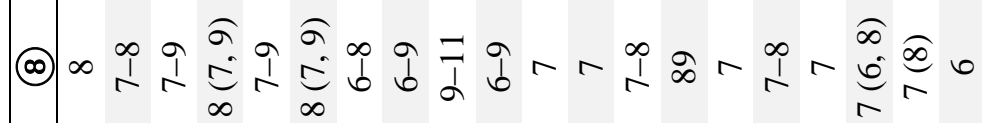

(1)

(4)

잉

(a)

(0)

की

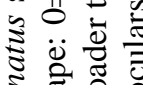

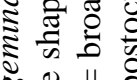

\& 0111 .

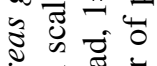

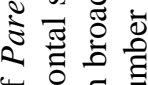

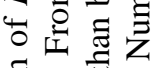

$\Theta \overbrace{\overline{0}}^{Z} \Theta_{0}^{\circ}$

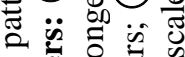

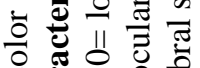

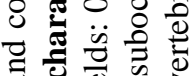

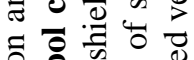

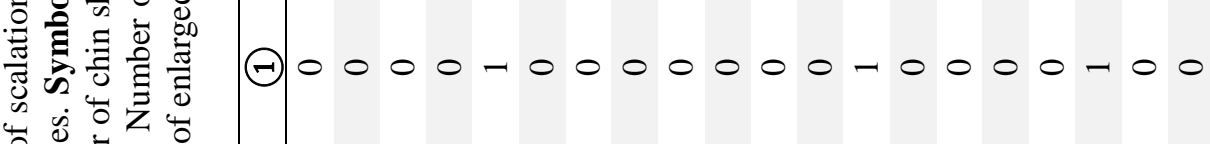

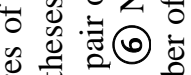

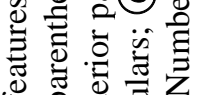

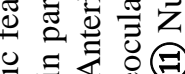

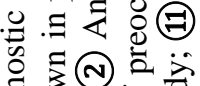

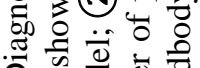

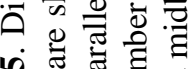

in

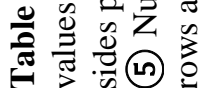

(a) $0000-0000000-0000-00$

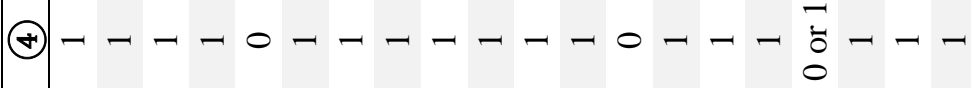

(i) $000-0$ छे000000000-00--
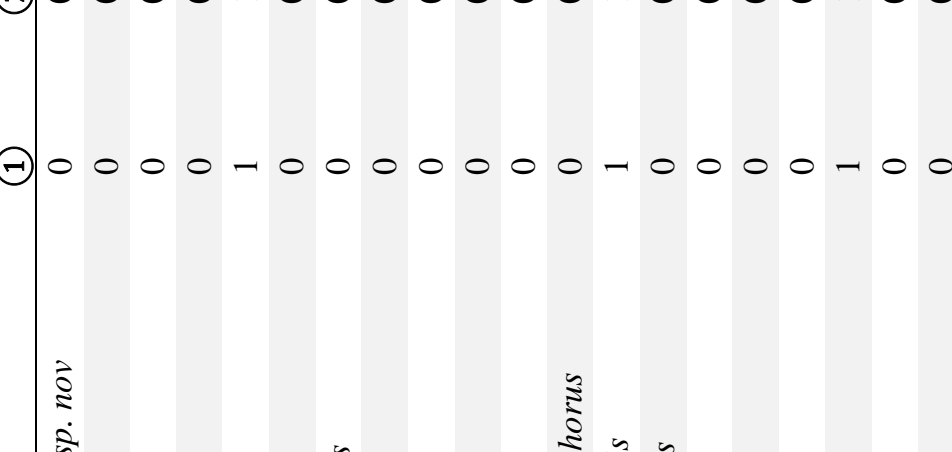

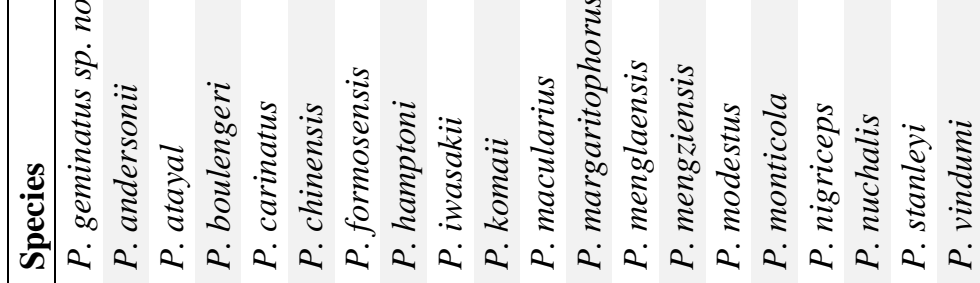




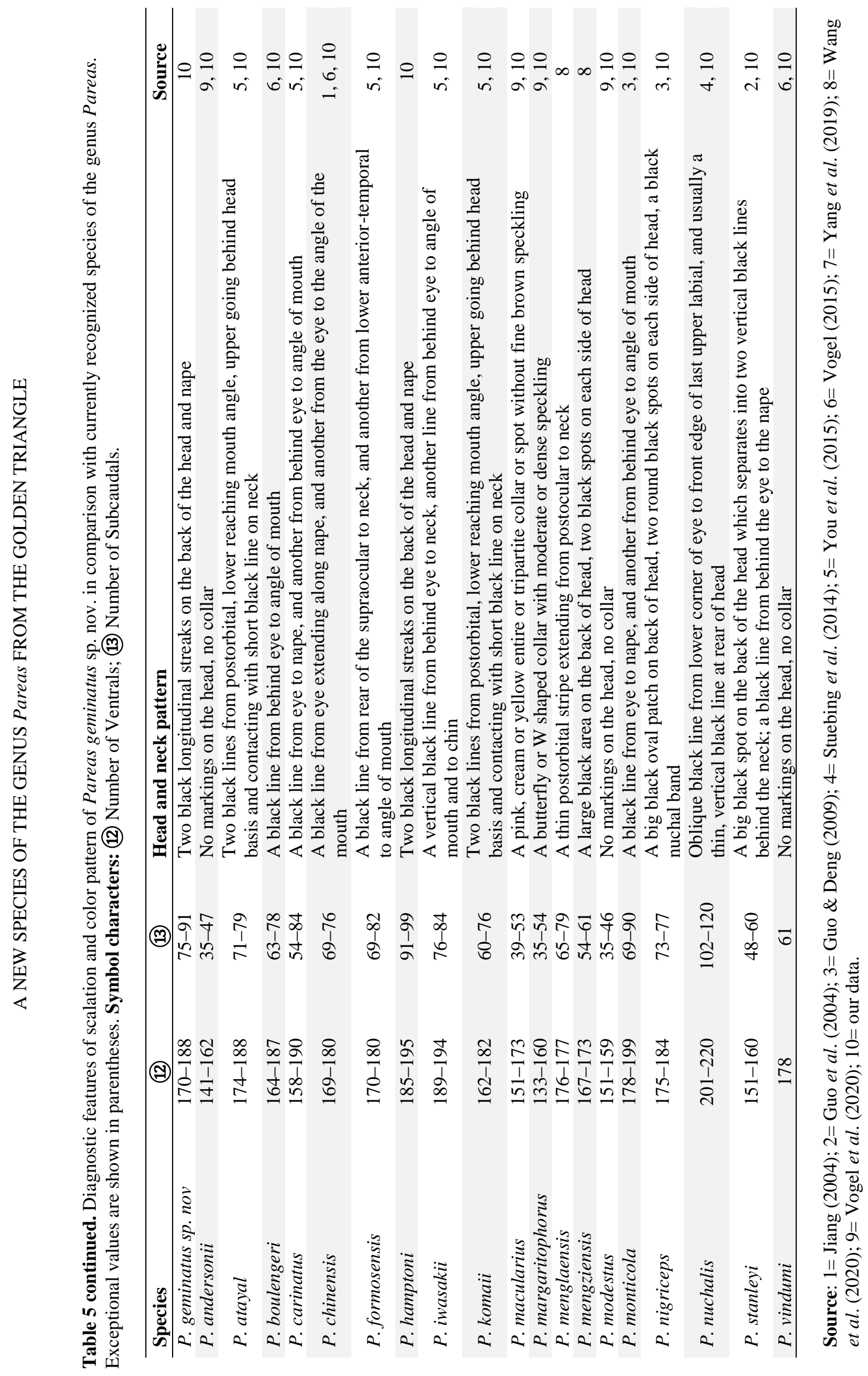




\section{Plate 52}
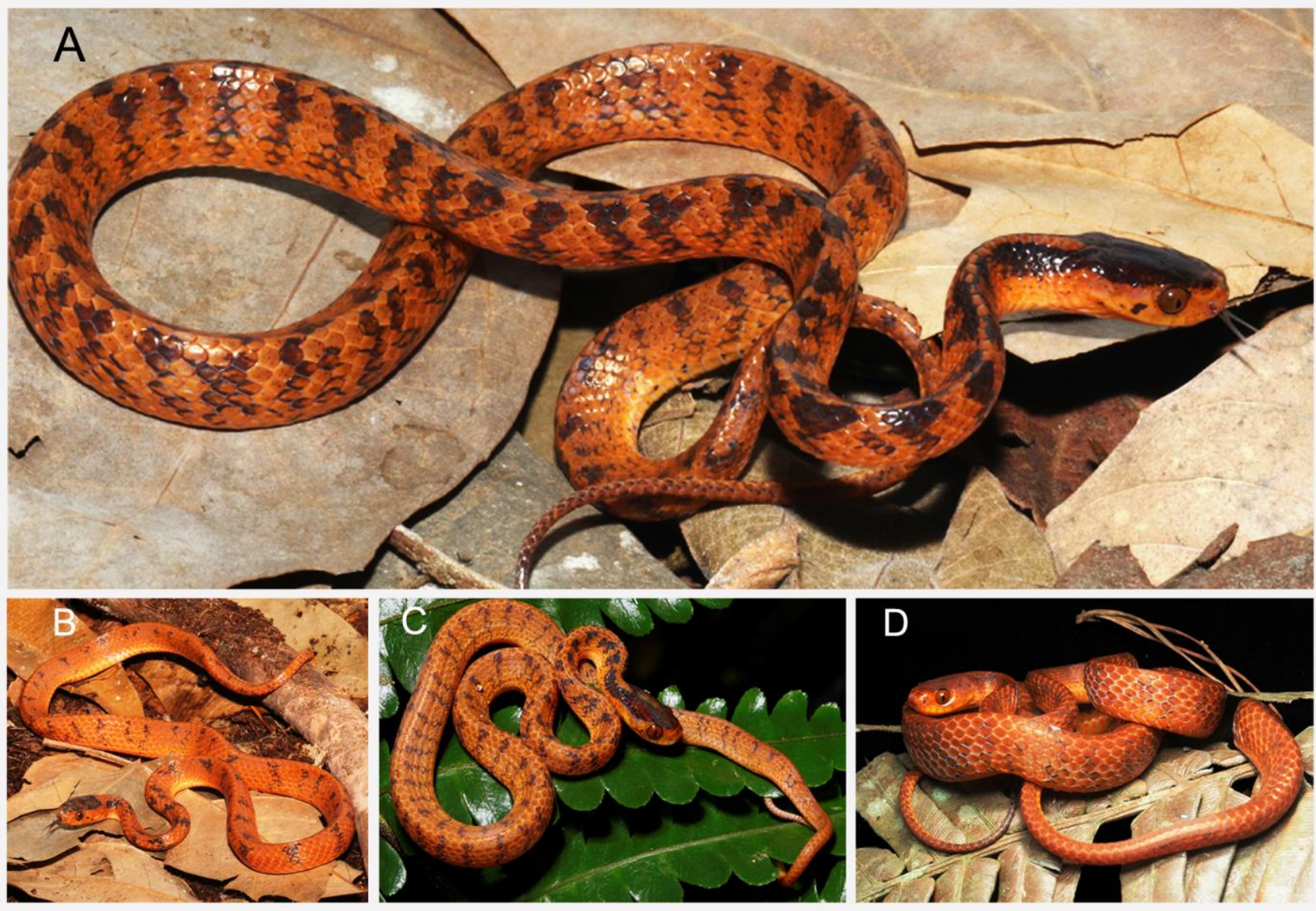

Figure 4. Pareas geminatus sp. nov. in life: (A \& B) adult males from Jiangchen County, Yunnan, China (not collected, (C) photos Shengchao Shi); (C) subadult male from Long Tien, Xaisomboun, Laos (ZMMU NAP09280, (C) photo Parinya Pawangkhanant); (D) adult male from Doi Inthanon NP, Chiang Mai, Thailand (AUP-00176, (C) photo N.A. Poyarkov)
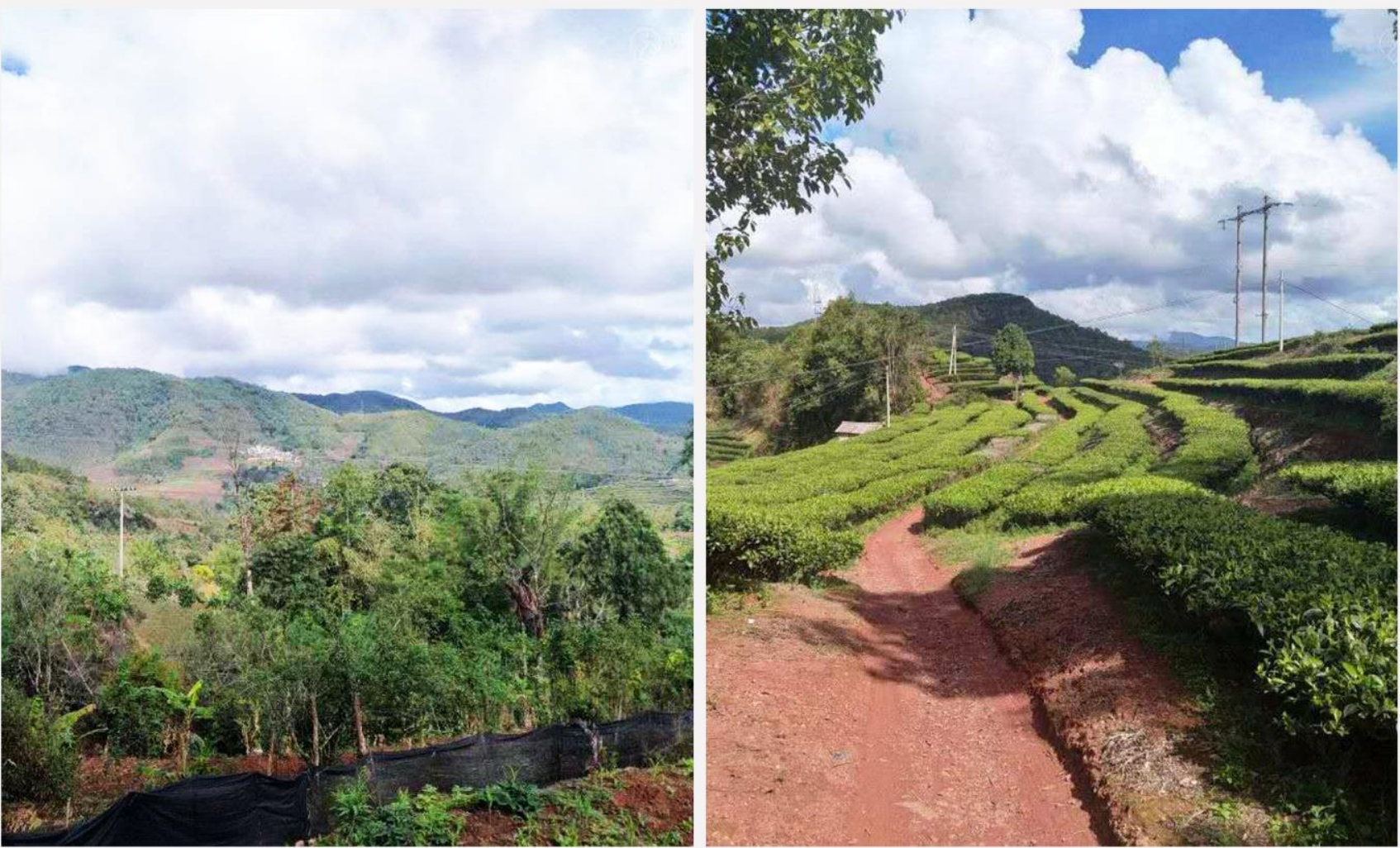

Figure 5. Habitats of Pareas geminatus sp. nov. (type locality) (C) photo Shengchao Shi 
Variation. Morphometric and meristic data for the type series are provided in Table 4 and Fig. 4. Paratypes generally agree with the holotype in scalation features. Some variation in body coloration is observed among specimens from China, Laos and Thailand. The topotype specimens from Jiangcheng County, Yunnan Province, China, vary in the degree of development of dark markings on dorsum, neck and dorsal surfaces: in some darker-colored specimens dark cross-bands on dorsum comprise two scales in width, and dark markings in nuchal area connect to dark brown spot covering almost all dorsal surfaces of the head (Fig. 4A), while in other specimens the dark patch on head abruptly terminates at the posterior edge of parietals, separated from much weaker nuchal dark markings by a light-orange collar (Fig. 4B). The adult male AUP-00176 is uniform reddishbrown dorsally, orange-yellow ventrally, with weak dark markings in nuchal area and on the dorsal surface of the head, and very weak almost indiscernible dorsal cross-bands (Fig. 4C). The characteristic dark postocular streaks are prominent in all specimens examined (Figs. 3, 4A-C) but the AUP-00176 (Fig. 4D). Iris reddish in life in all specimens.

Comparisons. Comparative morphological information of species considered to be diagnostic in the genus Pareas is summarized in Table 5. The new species is easily distinguishable from the $P$. margaritophorus group [including $\mathrm{P}$. andersonii, $P$. margaritophorus, $P$. macularius, and $P$. modestus] by pale brown body coloration with bands ( $v s$ uniform dark grey or with bicoloured dots); from the $P$. carinatus group [including $P$. carinatus, $P$. nuchalis, and $P$. menglaensis] by the frontal scale shape subhexagonal with the lateral sides converging posteriorly (vs hexagonal with the lateral sides parallel), the anterior pair of chin shields longer than broad ( $v s$ broader than long), the prefrontal contacting eye ( $v s$ not in contact), and one or two anterior temporals ( $v s$ usually three); from P. monticola by the loreal not contacting the eye ( $v s$ usually contacting), the absence of a presubocular ( $v s$ present), 3-5 slightly keeled dorsal scale rows at midbody ( $v s$ all smooth), and the eye separated from the labials by a subocular scale ( $v s 4^{\text {th }}$ or $4^{\text {th }}-5^{\text {th }}$ supralabials touching the eye); from $P$. boulengeri by the loreal not contacting the eye (vs usually contacting), 3-5 slightly keeled dorsal scale rows at midbody ( $v s$ usually all smooth), a single row of enlarged vertebral scales ( $v s$ vertebrals not enlarged), and a higher number of subcaudals 75-91 ( $v s$ 63-78); from $P$. chinensis by a single row of enlarged vertebral scales ( $v s 3$ rows) and a higher number of subcaudals 75-91 (vs 69-76); from P. stanleyi by the loreal not contacting the eye (vs usually contacting), the supralabials not touching the eye ( $v s$ in contact with the eye), a lower number of keeled dorsal scales at midbody 3-5 (vs 13), a single row of enlarged vertebral scales ( $v s$ not enlarged), a higher number of ventrals 170-188 (vs 151-160), and a higher number of subcaudals 75-91 (vs 48-60).

Comparisons of Pareas geminatus sp. nov. with other members of the $P$. hamptoni group appear to be the most pertinent. The new species differs from $P$. atayal by 3-5 medial dorsal scale rows slightly keeled at midbody (vs 5-9 strongly keeled scales), a single row of enlarged vertebral scales ( $v s 3$ rows), and the iris colour reddish ( $v s$ yellow); from $P$. iwasakii by 8 infralabials ( $v s$ 9-11) and a lower number of ventrals 170-188 (vs 189-194); from P. komaii by a lower number of keeled dorsal scales at midbody 3-5 (vs 913), a single row of enlarged vertebral scales ( $v s$ 3 rows), and a higher number of subcaudals 7591 (vs 60-76); from P. mengziensis by the pale brown coloration of dorsum with indistinct darker crossbars ( $v s$ solid black marking on back of head extending to dorsum), a single row of enlarged vertebral scales ( $v s 3$ rows), and a higher number of ventrals 170-188 (vs 167173); from $P$. nigriceps by a slightly higher number of subcaudals 75-91 (vs 73-77) and indistinct transverse bands on the body ( $v s$ distinct); from $P$. vindumi by the absence of a presubocular ( $v s$ presence), 7 supralabials (vs 6), a single row of enlarged vertebral scales ( $v s$ not enlarged), a higher number of subcaudals 75-91 (vs 61), and dark collar and cross bands on body present ( $v s$ absent); from $P$. formosensis by 3-5 dorsal scale rows at midbody keeled ( $v s$ all smooth) and a single row of enlarged vertebral scales ( $v s 3$ rows); and finally from its sister species, $P$. hamptoni, by 3-5 dorsal scale rows at midbody slightly keeled ( $v s \quad 5-9$ scales strongly keeled), a lower number of ventrals 170-188 (vs 185-195) and a lower number of subcaudals 67-91 (vs 91-99).

Moreover, the new species differs from the two species described from northern Vietnam (Eberhardtia tonkinensis Angel, 1920, type locality: Tam Dao NP., Vinh Phuc Province, Vietnam) and from Hainan Is. of China (Amblycephalus carinatus hainanus Smith, 
1923, type locality: Hainan) that are currently considered junior synonyms of $P$. hamptoni. Both of these species have completely smooth dorsal scale rows, which agrees with the diagnosis of $P$. formosensis and distinguishes them from the new species (3-5 slightly keeled dorsal scale rows at midbody in Pareas geminatus sp. nov.). As we demonstrate below, based on the analysis of topotypic material from northern Vietnam and Hainan, Eberhardtia tonkinensis Angel, 1920 and Amblycephalus carinatus hainanus Smith, 1923 have to be considered junior synonyms of $P$. formosensis.

Etymology. The specific epithet "geminatus" is a Latin adjective in nominative singular (masculine gender) derived from the Latin "geminus", for "twin", "double", and is given in reference to the similarity in morphology of the new species to its sister taxon, $P$. hamptoni, with which it was confused for a long time. We suggest the following common names: "Twin Slug snake" (English) and "Bó Zhòng Dùn Tóu Shê" (伯仲钝头蛇) in Chinese.

Distribution and natural history. The known distribution of Pareas geminatus sp. nov. is shown in Fig. 1. The new species is currently known from the Golden Triangle area, including the southernmost part of Yunnan Province, the northwestern part of Thailand, and the northern part of Laos. The occurrence of the new species in the extreme eastern corner of the Shan Plateau in Myanmar is anticipated. At the type locality in Jiangcheng County, Yunnan, China, Pareas geminatus inhabits tropical monsoon forests with clearly defined dry and wet seasons at elevations from 1,160 to $2,280 \mathrm{~m}$ asl. The new species was also recorded in highly modified secondary habitats with tea plantations (Fig. 5). The specimens of Pareas geminatus were observed at night after $2100 \mathrm{~h}$ while perching on vines or bushes ca. 1.0-1.5 m above the ground, waiting for prey. In China, the new species is threatened by intensifying human activity due to increasing deforestation for tea cultivation.

Conservation status. Further research is required to clarify the extent of the distribution, population trends and conservation status of the new species. Pareas geminatus sp. nov. is distributed over a large area including several protected areas. Across its range the new species seems not to be especially rare. Thus, we tentatively suggest $P$. geminatus be considered a Least Concern (LC) species following the IUCN's Red List categories (IUCN Standards and Petitions Committee 2019).

\section{Discussion}

Our study provides an updated phylogeny for the genus Pareas including 20 nominal species and one undescribed population, Pareas sp. from Indian East Himalayas (Fig. 1, locality 1). Our phylogenetic results are concordant with the earlier works (You et al. 2015, Wang et al. 2020, Vogel et al. 2020) in recognizing the monophyly of the genus Pareas encompassing five major species groups (Fig. 2A-E). Though the phylogenetic relationships within the $P$. hamptoni species group remain essentially unresolved, our study provides insights on diversity and distribution of the group members.

The undescribed Pareas sp. from India forms a well-supported clade (98/1.0) with $P$. nigriceps from Mt. Gaoligongshan in western Yunnan. Monophyly of the clade encompassing the three species from the East Asian islands (Taiwan and Yaeyama Group: $P$. atayal, $P$. iwasakii, and $P$. komaii) is strongly supported (100/1.0) (Fig. 2).

Pareas vindumi from the northeastern part of Kachin State of Myanmar, which originally described without assignment to any species group of Pareas (Vogel 2015), is confirmed as the member of $P$. hamptoni species group (Fig. 2). We have for the first time confirmed the actual distribution limits of $P$. formosensis, which remained unclear after the review by Wang et al. (2020). According to our data, this species inhabits not only the island of Taiwan, but also the southern parts of mainland China including Guangdong Province, Hainan Island, and is also found in Vietnam from the north (Cao Bang and Vinh Phuc provinces) southwards along the Truong Son (Annamite) Mountain Range to the Kontum and Langbian plateaus in the south (Fig. 1: localities 17-27), and most certainly also can be found in the Cambodian and Laotian parts of the Annamite Range.

Eberhardtia tonkinensis Angel, 1920 (from Tam Dao NP., Vinh Phuc Province, northern Vietnam, Fig. 1: locality 22) and Amblycephalus carinatus hainanus Smith, 1923 (from Hainan, Fig. 1: locality 24) were examined and fall into the range of $P$. formosensis sensu lato and also agree with the morphological diagnosis of the latter species (smooth dorsal scales). With this new data we now consider Eberhardtia tonkinensis Angel, 1920 and Amblycephalus carinatus hainanus Smith, 1923 to be subjective junior synonyms of Amblycephalus formosensis van Denburgh, 1909. 
Several Pareas species described from southern China in the early $20^{\text {th }}$ century and presently considered junior synonyms of $P$. chinensis (Wallach et al. 2014) or P. hamptoni (Uetz et al. 2020) still remain poorly understood. The type localities of Amblycephalus yunnanensis Vogt, 1922 and Amblycephalus niger Pope, 1928 are also located in the northern part of Yunnan Province, China (Fig. 1: localities 8-9); both species may represent valid taxa according to our ongoing studies. The type locality of Amblycephalus kuangtungensis Vogt, 1922 described from Guangdong Province in southern China (Fig. 1: locality 28) is placed within the range of $P$. formosensis sensu lato, and it is likely that they are conspecific. The identity of these three taxa has yet to be clarified based on an integrative approach combining morphological examination of type specimens and molecular data from the topotypic materials.

Despite the fact that $P$. hamptoni has been known since 1905 and is regularly mentioned in scientific publications, this species seems to be very rare in collections. Most specimens that we located actually belong to $P$. geminatus sp. nov. or to $P$. formosensis. It is not clear whether the distributions of $P$. hamptoni and $P$. geminatus sp. nov. overlap but it seems to be likely that both species live in sympatry in the southwestern part of China. The sympatry of three other members of the $P$. hamptoni group ( $P$. formosensis, $P$. komaii, and $P$. atayal) was recently reported from Taiwan Island (You et al. 2015); however such cases are not yet known from the Asian mainland. Although we do not report different species of the $P$. hamptoni group occurring sympatric in the present paper, the demonstrated high diversity of the group members in the mountains of southern Yunnan and northwestern Vietnam implies that some of them might be found in sympatry. Pareas vindumi and $P$. nigriceps are expected to be sympatric with $P$. hamptoni sensu stricto in the montane areas of western Yunnan and the eastern part of Kachin State of Myanmar. The ranges of $P$. hamptoni sensu stricto, $P$. geminatus sp. nov. and $P$. mengziensis most surely overlap in southern Yunnan, while $P$. formosensis is distributed to the east of the range of $P$. geminatus sp. nov., and the cases of sympatric or parapatric occurrence of these two species cannot be excluded in northern Vietnam and Laos. Finally, the significant degree of molecular divergence along with the differences in morphology and coloration observed between the populations of $P$. geminatus sp. nov. from China, Laos and Thailand suggest that further studies on the phylogeography and distribution patterns of this new species are required to assess its intraspecific variation.

\section{Acknowledgements}

We thank the Laboratory Animal Research Center (University of Phayao); The Institute of Animal for Scientific Purposes Development (IAD), Thailand; and the Department of National Parks, Wildlife and Plant Conservation (DNP), Thailand for permission to conduct field work. Specimen collection protocols and animal use were approved by the Institutional Ethical Committee of Animal Experimentation of the University of Phayao, Thailand (certificate number UP-AE61-01-04-0022 issued to Chatmongkon Suwannapoom). Fieldwork, including the collection of animals in the field and specimen exportation, was authorised by the Institute of Animals for Scientific Purpose Development (IAD), Bangkok, Thailand (permit number U1-01205-2558, issued to Chatmongkon Suwannapoom). Fieldwork in Laos was granted by the Biotechnology and Ecology Institute Ministry of Science and Technology, Lao PDR (permit no. 009 of 23 June 2020). Fieldwork in Vietnam was funded and supported by the Joint Russian-Vietnamese Tropical and Technological Center (JRVTTC) and was conducted with the permission of the local administration. Also we thank Andrey N. Kuznetsov (JRVTTC) and Thai Van Nguyen (SVW) for supporting our study, and Parinya Pawangkhanant, Peter Brakels, Sabira S. Idiiatullina and Platon V. Yushchenko for support and assistance both in the field and in the lab. NAP thanks Si-Min Lin and Chung-Wei You (NTNU, Taipei, Taiwan) for the support. Colin McCarthy and Patrick Campbell at NHMUK, London; Jens Vindum and Alan Leviton at CAS, California; Yuezhao Wang, Xiaomao Zeng, Jiatang $\mathrm{Li}$ and Ermi Zhao at CIB, Chengdu; Alan Resetar at FMNH, Chicago; Silke Schweiger and Georg Gassner at NMW, Vienna; Nicolas Vidal and Annemarie Ohler at MNHN, Paris; Lawan Chanhome at QSMI, Bangkok; Oliver Rödel and Frank Tillack at ZMB, Berlin; and Jakob Hallermann at $\mathrm{ZMH}$, Hamburg are acknowledged for providing access to specimen collections under their care and their support during our visits. Alan Leviton (CAS) is thanked for the invitation 
of GV to CAS. Jia Tang Li is thanked for his support of the work of GV in China. We thank Shengchao Shi and Parinya Pawangkhanant for taking photographs and Christopher James Oldnall for proofreading the manuscript and linguistic help. We express our sincere gratitude to Indraneil Das (University of Malaysia, Sarawak), Patrick David (MNHN), and Thasun Amarasinghe (University of Indonesia) for reviewing the manuscript. Fieldwork, specimen collection, and molecular phylogenetic analysis was conducted with the financial support of the Russian Science Foundation (RSF Grant No. 1914-00050 to Nikolay A. Poyarkov, molecular analysis). This work was partially supported by the Biodiversity Investigation, Observation and Assessment Program of Ministry of Ecology and Environment of China (2019-2023) to Zening Chen, and by the Unit of Excellence 2020 on Biodiversity and Natural Resources Management, University of Phayao (UoE63005) to Chatmongkon Suwannapoom.

\section{Literature cited}

Alencar, L.R., T.B. Quental, F.G. Grazziotin, M.L. Alfaro, M. Martins et al. (2016). Diversification in vipers: Phylogenetic relationships, time of divergence and shifts in speciation rates. Molecular Phylogenetics \& Evolution, 105: 50-62.

Angel, F. (1920). Sur deux Ophidiens nouveaux de la collection du Muséum. Bulletin du Muséum National d'Histoire Naturelle, 26 (4): 291294.

Boulenger, G.A. (1905). Descriptions of two new snakes from Upper Burma. Journal of the Bombay Natural History Society, 16: 235-236.

de Queiroz, A., R. Lawson, and J.A. LemosEspinal (2002). Phylogenetic relationships of North American garter snakes (Thamnophis) based on four mitochondrial genes: how much DNA is enough? Molecular Phylogenetics \& Evolution, 22: 315-329.

Deepak, V., S. Narayanan, S. Das, K.P. Rajkumar, P.S. Easa et al. (2020). Description of a new species of Xylophis Beddome, 1878 (Serpentes: Pareidae: Xylophiinae) from the Western Ghats, India. Zootaxa, 4755: 231250.

Deepak, V., S. Ruane, and D.J. Gower (2018). A new subfamily of fossorial colubroid snakes from the Western Ghats of peninsular India. Journal of Natural History, 52 (45-46): 29192934.
Dowling, H.G. (1951). A proposed standard system of counting ventrals in snakes. British Journal of Herpetology, 1: 97-99.

Figueroa, A., A.D. McKelvy, L.L. Grismer, C.D. Bell, and S.P. Lailvaux (2016). A species-level phylogeny of extant snakes with description of a new colubrid subfamily and genus. PloS One, 11(9): e0161070.

Grossmann, W. and F. Tillack (2003). On the taxonomic status of Asthenodipsas tropidonotus (van Lidth de Jeude, 1923) and Pareas vertebralis (Boulenger, 1900) (Serpentes: Colubridae: Pareatinae). Russian Journal of Herpetology, 10 (3): 175-190.

Guo, K. and X. Deng (2009). A new species of Pareas (Serpentes: Colubridae: Pareatinae) from the Gaoligong Mountains, southwestern China. Zootaxa, 2008: 53-60.

Guo, P. and E.-M. Zhao (2004). Pareas stanleyiA record new to Sichuan, China and a key to the Chinese species. Asiatic Herpetological Research, 10: 280-281.

Guo, Y., Y. Wu, S. He, H.A. Shi, and E.-M. Zhao (2011). Systematics and molecular phylogenetics of Asian snail-eating snakes (Pareatidae). Zootaxa, 3001 (1): 57-64.

Hall, T.A. (1999). BioEdit: a user-friendly biological sequence alignment editor and analysis program for Windows 95/98/NT. Nucleic acids symposium series. Information Retrieval Ltd., London: 95-98 (c1979-c2000).

Hillis, D.M., C. Moritz, and B.K. Mable (1996). Molecular Systematics. Second Edition. Sinauer Associates, Massachusetts: 655pp.

Hoang, D.T., O. Chernomor, A. von Haeseler, M.Q. Bui, and V.S. Le (2018). UFBoot2: Improving the ultrafast bootstrap approximation. Molecular Biology \& Evolution, 35: 518-522.

Huelsenbeck, J.P. and D.M. Hillis (1993). Success of phylogenetic methods in the four-taxon case. Systematic Biology, 42 (3): 247-264.

Huelsenbeck, J.P., and F. Ronquist (2001). MRBAYES: Bayesian inference of phylogenetic trees. Bioinformatics, 17 (8): 754-755.

IUCN Standards and Petitions Subcommittee (2019). Guidelines for Using the IUCN Red List Categories and Criteria. Version 14. Prepared by the Standards and Petitions Subcommittee, IUCN: 113pp.

Jiang, Y.M. (2004). Pareas chinensis (Babour, 1912) should be a junior synonym of Pareas formosensis (Van Denburgh, 1909) [in Chinese]. Sichuan Journal of Zoology, 23: 209-210. 
Jobb, G. (2011). TREEFINDER: March 2011 <www.treefinder.de>

Kalyaanamoorthy, S., B.Q. Minh, T.K. Wong, A. von Haeseler, and L.S. Jermiin (2017). ModelFinder: fast model selection for accurate phylogenetic estimates. Nature Methods, 14: 587.

Katoh, K., K. Misawa, K. Kuma, and T. Miyata (2002). MAFFT: a novel method for rapid multiple sequence alignment based on fast Fourier transform. Nucleic Acids Research, 30 (13): 3059-3066.

Kraus, F. and W.M. Brown (1998). Phylogenetic relationships of colubroid snakes based on mitochondrial DNA sequences. Zoological Journal of the Linnean Society, 122 (3): 455487.

Li, J.-N., D. Liang, Y.-Y. Wang, P. Guo, S. Huang et al. (2020). A large-scale systematic framework of Chinese snakes based on a unified multilocus marker system. Molecular Phylogenetics \& Evolution, 148: 106807.

Loredo, A.I., P.L. Wood, E.S.H. Quah, S. Anuar, L.F. Greer et al. (2013). Cryptic speciation within Asthenodipsas vertebralis (Boulenger, 1900) (Squamata: Pareatidae), the description of a new species from Peninsular Malaysia, and the resurrection of $A$. tropidonotus (Lidth de Jude, 1923) from Sumatra: an integrative taxonomic analysis. Zootaxa, 3664: 505-524.

Maki, M. (1931). A monograph of the snakes of Japan [In Japanese]. Dai-ichi Shobo, Tokyo, 240pp.

Maki, M. (1937). A new subspecies, Amblycephalus formosensis iwasakii, belonging to Amblycephalidae from Ishigakijima. Transactions of the Natural History Society of Formosa [In Japanese]. Taihoku, 27 (169): 217-218.

Minh, B.Q., M.A.T. Nguyen, and A. von Haeseler (2013). Ultrafast approximation for phylogenetic bootstrap. Molecular Biology \& Evolution, 30: 1188-1195.

Nguyen, L.T., H.A. Schmidt, A. Haeseler, and Q.M. Bui (2015). IQ-TREE: a fast and effective stochastic algorithm for estimating maximum-likelihood phylogenies. Molecular Phylogenetics \& Evolution, 32: 268-274.

Nguyen, S.V., C.T. Ho, and T.Q. Nguyen (2009). Herpetofauna of Vietnam. Edition Chimaira, Frankfurt: 768pp.

Nguyen, T.V., P. Brakels, N. Maury, S. Sudavanh, P. Pawangkhanant et al. (2020). New herpetofaunal observations from Laos based on photo records. Amphibian \& Reptile Conservation, 14 (2): 218-249 (e248).
Pope, C.H. (1928). Four new snakes and a new lizard from South China. American Museum Novitates, 325: 1-4.

Rambaut, A. and A.J. Drummond (2007). Tracer v1. 5 <http://beast.bio.ed.ac.uk/Tracer>.

Ronquist, F. and J.P. Huelsenbeck (2003). MRBAYES 3: Bayesian phylogenetic inference under mixed models. Bioinformatics, 19: 1572-1574.

Salvi, D., D.J. Harris, A. Kaliontzopoulou, M.A. Carretero, and C. Pinho (2013). Persistence across Pleistocene ice ages in Mediterranean and extra-Mediterranean refugia: Phylogeographic insights from the common wall lizard. BMC Evolutionary Biology, 13: 147.

Shimodaira H. (2002). An approximately unbiased test of phylogenetic tree selection. Systematic Biology, 51(3): 492-508.

Slowinski, J.B. and R. Lawson (2002). Snake phylogeny: evidence from nuclear and mitochondrial genes. Molecular Phylogenetics \& Evolution, 24 (2): 194-202.

Smith, M.A. (1923). On a collection of reptiles and batrachians from the island of Hainan Journal of the Natural History Society of Siam, 6: 195212.

Stuebing, R.B., R.F. Inger, and B. Lardner (2014). A field guide to the snakes of Borneo. 2nd Edition.Natural History Publications (Borneo), Kota Kinabalu: 310pp.

Tamura, K., G. Stecher, D. Peterson, A. Filipski, and S. Kumar (2013). MEGA6: molecular evolutionary genetics analysis version 6.0. Molecular Biology and Evolution, 30 (12): 2725-2729.

Teynié, A. and P. David (2010). Voyages naturalistes au Laos: les Reptiles. Revoir Editions, Nohanent: 315pp.

Trifinopoulos, J., T.L. Nguyen, A. von Haeseler, and MQ. Bui (2016). W-IQ-TREE: a fast online phylogenetic tool for maximum likelihood analysis. Nucleic Acids Research, 44: W232-W235.

Uetz, P., P Freed, and J. Hošek (2020). The Reptile Database <www.reptiledatabase.reptarium. cz> Accessed on 14 October 2020.

Van Denburgh, J. (1909). New and previously unrecorded species of reptiles and amphibians from the island of Formosa. Proceedings of California Academy of Sciences, 4 (3): 49-56.

Vogel, G. (2010). On the distribution of Pareas hamptoni (Boulenger, 1905) in Thailand (Serpentes: Pareatinae). Russian Journal of Herpetology, 17(3): 219-222.

Vogel, G. (2015). A new montane species of the genus Pareas Wagler, 1830 (Squamata: 
Pareatidae) from northern Myanmar. Taprobanica, 7: 1-7.

Vogel, G., T.V. Nguyen, H.T. Lalremsanga, L. Biakzuala, V. Hrima, and N.A. Poyarkov (2020). Taxonomic reassessment of the Pareas margaritophorus-macularius species complex (Squamata, Pareidae). Vertebrate Zoology, 70 (4): 547-569.

Vogt, T. (1922). Zur Reptilien- und Amphibienfauna Südchinas. Archiv für Naturgeschichte, 88A (10): 135-146.

Wagler, J.G. (1830). Natürliches System der Amphibien, mit vorangehender Classification der Säugethiere und Vögel. Ein Beitrag zur vergleichenden Zoologie. J.G. Cottáschen Buchhandlung. Stuttgart und Tübingen, München: 354 pp.

Wallach, V., Williams, K.L., and J. Boundy (2014). Snakes of the world: a catalogue of living and extinct species. CRC press, Boca Raton: $1237 \mathrm{pp}$.
Wang, P., J. Che, Q. Liu, K. Li, J.Q. Jin et al. (2020). A revised taxonomy of Asia snaileating snakes Pareas (Squamata, Pareidae): evidence from morphological comparison and molecular phylogeny. ZooKeys, 939: 45-64.

Wilcox, T.P., D.J. Zwickl, T.A. Heath, and D.M. Hillis (2002). Phylogenetic relationships of the Dwarf Boas and a comparison of Bayesian and bootstrap measures of phylogenetic support. Molecular Phylogenetics \& Evolution, 25: 361-371.

You, C.-W., N.A. Poyarkov, and S.-M. Lin (2015). Diversity of the snail-eating snakes Pareas (Serpentes, Pareatidae) from Taiwan. Zoologica Scripta, 44: 349-361.

Appendix. Specimens Examined

Pareas atayal (4 ex.): Taiwan: Yang-Ming-Shan: FMNH 169392; Yang-Ming-Shan: Yung-foh-lee: FMNH 127998, 169315; Yang-Ming-Shan: Mt. Agr. Area: FMNH 169395.

Pareas boulengeri (9 ex.): China: Kouy Tcheounow, Guizhou Province: MNHN 1912.0349-0351 (syntypes of Amblycephalus boulengeri); Fangxiang Village, Leishan County, Guizhou Province: CIB 10084; Ebian County, Sichuan Province: DL 026; Xingou village, Ya'an City, Sichuan Province: DL 2019.09.23.04; Xianju County, Zhejiang Province: DL 2018.06.29.01-02.

Pareas chinensis (7 ex.): China: Mt. Jiguan, Sichuan Province: DL 051; Hongya Xian, Sichuan Province: FMNH 232812-14; Sichuan Province: FMNH 170632; Mt. Jiguan, Sichuan Province: NMW 39540.1-2.

Pareas formosanus (12 ex.): Taiwan: Tsu-Shari: NMW 28130:3, 7-9; Formosa: NMW 28130:12, 14, 16, 18; Kosango: NMW 28130:20; Suisharya: ZMB 30585. Vietnam: Lao-Kay (now Sapa District, Lao Cai Province): MNHN 1908.206 (holotype of Eberhardtia tonkinensis). China: Kachei near Five Finger Mount, Hainan Province: NHMUK 1924.5.22.11 (holotype of Amblycephalus carinatus hainanus).

Pareas hamptoni (5 ex.): Myanmar: Mogok, Upper Burma now Mandalay Division: NHMUK 1904.4.26.16 (holotype of Amblycephalus hamptoni); Naung Mon, Putao District, Kachin State: CAS 221489. Vietnam: Sa Pa District, Lao Cai Province: MNHN-RA 1935.0087-88, RMNH 6512.

Pareas stanleyi (4 ex.): China: Fujian Province: CIB 10165; Fukien, Ch'unganHsien now Wuyishan City, Fujian Province: FMNH 24990-92.

Pareas vidumi (1 ex.): Myanmar: Chipwi Township, Lukpwi Village, Kachin State: CAS 248147 (holotype of Pareas vidumi).

Pareas monticola (24 ex.): India: Naga Hillas, Assam: NHMUK 1946.1.20.5 (holotype of Dipsas monticola); Khasi Hills, Meghalaya: NHMUK 1907.12.16.26, 60.3.19.1312; Darjiling, west Bengal: NHMUK 1909.3.9.18-21, 80.11.10.147, NMW 28127, ZMH R05510; Jaipur, Rajasthan" (erroneous): NHMUK 1910.12.36.7; Mishmi Hills, Arunachal Pradesh: NHMUK 1940.3.7.2; Abor Hills, Arunachal Pradesh: NHMUK 1940.3.9.15-16; Mizoram: MZMU 851, 1335, 1485-1486. China: Motuo, Xizang: CIB 10163. Myanmar: Indawgyi, Kachin: ZMMU R-16630; Ban Mauk, Sagaing: ZMMU R-16631-16634.

Pareas geminatus sp. nov. (12 ex.): China: Jiangcheng, Yunnan Province: CIB 118021-23, DL20190930001-2, DL2019072910. Laos: Houaphanh Province: MNHN 171S; Long Tien, Xaisomboun Province: ZMMU R-16695. Thailand: Tak Province: QSMI 1013; Doi Inthanon NP, Chiang Mai Province: AUP-00176, ZMMU R-16477-8. 